OPEN ACCESS

Edited by:

Wei Zhao,

City University of Hong Kong,

China

Reviewed by:

Chunming Cheng,

The Ohio State University,

United States

Pier Giorgio Petronini,

University of Parma, Italy

${ }^{*}$ Correspondence:

Monde Ntwasa

ntwasmm@unisa.ac.za

${ }^{\text {t}}$ These authors have contributed equally to this work

Specialty section: This article was submitted to Molecular and Cellular Oncology, a section of the journal

Frontiers in Oncology

Received: 14 December 2020 Accepted: 16 June 2021

Published: 29 June 2021

Citation:

Russell BL, Sooklal SA, Malindisa ST, Daka LJ and Ntwasa M (2021) The

Tumor Microenvironment Factors That

Promote Resistance to Immune Checkpoint Blockade Therapy.

Front. Oncol. 11:641428.

doi: 10.3389/fonc.2021.641428

\section{The Tumor Microenvironment Factors That Promote Resistance to Immune Checkpoint Blockade Therapy}

\author{
Bonnie L. Russell ${ }^{1,2 \dagger}$, Selisha A. Sooklal ${ }^{1 \dagger}$, Sibusiso T. Malindisa ${ }^{1 \dagger}$, \\ Lembelani Jonathan Daka ${ }^{2}$ and Monde Ntwasa ${ }^{1 *}$ \\ ${ }^{1}$ Department of Life \& Consumer Sciences, University of South Africa, Johannesburg, South Africa, ${ }^{2}$ Innovation Hub, Buboo \\ (Pty) Ltd, Pretoria, South Africa
}

Through genetic and epigenetic alterations, cancer cells present the immune system with a diversity of antigens or neoantigens, which the organism must distinguish from self. The immune system responds to neoantigens by activating naïv $T$ cells, which mount an anticancer cytotoxic response. T cell activation begins when the T cell receptor (TCR) interacts with the antigen, which is displayed by the major histocompatibility complex (MHC) on antigen-presenting cells (APCs). Subsequently, accessory stimulatory or inhibitory molecules transduce a secondary signal in concert with the TCR/antigen mediated stimulus. These molecules serve to modulate the activation signal's strength at the immune synapse. Therefore, the activation signal's optimum amplitude is maintained by a balance between the costimulatory and inhibitory signals. This system comprises the so-called immune checkpoints such as the programmed cell death (PD-1) and Cytotoxic T lymphocyte-associated antigen-4 (CTLA-4) and is crucial for the maintenance of self-tolerance. Cancers often evade the intrinsic anti-tumor activity present in normal physiology primarily by the downregulation of $T$ cell activation. The blockade of the immune checkpoint inhibitors using specific monoclonal antibodies has emerged as a potentially powerful anticancer therapy strategy. Several drugs have been approved mainly for solid tumors. However, it has emerged that there are innate and acquired mechanisms by which resistance is developed against these therapies. Some of these are tumor-intrinsic mechanisms, while others are tumor-extrinsic whereby the microenvironment may have innate or acquired resistance to checkpoint inhibitors. This review article will examine mechanisms by which resistance is mounted against immune checkpoint inhibitors focussing on anti-CTL4-A and anti-PD-1/PD-LI since drugs targeting these checkpoints are the most developed.

Keywords: PD-1, CTLA-4, Immune checkpoint inhibitor, resistance, tumor microenvironment 


\section{INTRODUCTION}

Cancers often evade the intrinsic anti-tumor activity present in normal physiology through various mechanisms one of which is the downregulation of $\mathrm{T}$ cell activation. Through genetic and epigenetic alterations, cancer cells present the immune system with a diversity of antigens, which are distinguishable from self. Antigen-specific $\mathrm{T}$ cell activation is initiated by a signal mediated by the interaction of the $\mathrm{T}$ cell receptor (TCR) with an antigen that is bound to the major histocompatibility complex (MHC) on antigen presenting cells and another signal transduced through co-stimulatory molecules belonging to the B7 family. The optimum amplitude of activation signal is maintained by a balance between this costimulatory signal and an inhibitory one also mediated by the B7 family (1). This system comprises the so-called immune checkpoints mediated by the inhibitory molecules and is crucial for the maintenance of self-tolerance. The blockade of the immune checkpoint inhibitors has emerged as a potentially powerful strategy for anti-cancer therapy and several drugs, mainly for solid tumors, have been approved (Table 1) $(35,36)$.

Cancers develop within a diverse and dynamic microenvironment and possess mechanisms to survive unfavourable physiological machinery designed to suppress carcinogenesis. Thus, they are equipped with strategies to reprogram the microenvironment metabolically and immunologically. For example, cancers develop mechanisms to switch off the physiological immune response by blocking activated $\mathrm{T}$ cells to protect themselves from cytotoxic killing. Thus, during cancer progression, the immune checkpoint pathways mediated by the structurally similar co-inhibitory receptors; Programmed cell Death 1 (PD-1) and the Cytotoxic T lymphocyte-associated antigen-4 (CTLA-4) or CD152 receptors are often usurped by cancer cells to evade immune surveillance. These two receptors, which form part of a growing list of checkpoint inhibitors, are the foremost targets for immune checkpoint inhibition-based drug development in recent years (Table 1).

TABLE 1 | List of FDA-approved Immune Checkpoint Inhibitors (ICls) targeting CTLA-4, PD-1 and PD-L1.

\begin{tabular}{|c|c|c|}
\hline Drug (Trade name) & Company & Date of approval \\
\hline
\end{tabular}

\begin{tabular}{lcc} 
Drug (Trade name) & Company & Date of approval \\
\hline CTLA-4 inhibitors & & 2011 \\
Ipilimumab $\left(\right.$ Yervoy $\left.^{\circledR}\right)$ & Bristol-Myers Squibb &
\end{tabular}

PD-1 inhibitors

Nivolumab (Opdivo $\left.{ }^{\circledR}\right)$

Bristol-Myers Squibb

Merck

Cemiplimab (Libtayo ${ }^{\circledR}$ )

PD-L1 inhibitors

Atezolizumab (Tecentriq ${ }^{\circledR}$ )

Avelumab (Bavencio ${ }^{\circledR}$ )

Durvalumab (Imfinzi $\left.{ }^{\circledR}\right)$
Sanofi

Roche, Genentech

Merck, Pfizer

AstraZeneca
2014

2018

2014

2016

2017

2017
Melanoma

colorectal cancer

Renal cell carcinoma

(2)

(3)

(4)

Melanoma

(5)

Hodgkin's lymphoma

Diffuse large B-cell lymphoma

Urothelial cancer

Colorectal cancer

Hepatocellular carcinoma

Non-small cell lung cancer

Small cell lung cancer

Renal cell carcinoma

Squamous cell carcinoma

Melanoma

Cervical cancer

Hodgkin's lymphoma

Diffuse large B-cell lymphoma

Gastric cancer

Urothelial cancer

Colorectal cancer

Hepatocellular carcinoma

Non-small cell lung cancer

Small cell lung cancer

Renal cell carcinoma

Squamous cell carcinoma

Esophageal cancer

Merkel cell carcinoma

Cutaneous squamous cell carcinoma

Non-small cell lung cancer

Triple negative breast cancer

Merkel cell carcinoma

Renal cell carcinoma

Urothelial cancer

Bladder cancer

Non-small cell lung cancer 
In this review we examine the mechanisms of inhibitors targeting the immune checkpoint pathways PD-1/PD-L1 and CTLA-4, as well as the types of resistance that can develop against them.

\section{CTLA-4 AND PD-1 IMMUNE CHECKPOINT SIGNALLING PATHWAYS}

The CTLA-4, which is the first co-inhibitory immune checkpoint receptor to be identified, is constitutively expressed on both CD4+ and CD8+ T lymphocytes (37). CD28 and CTLA-4 are both capable of binding two important ligands, namely B7.1 (also known as CD80) and B7.2 (also known as CD86) (38). CTLA-4 expression is up regulated in $\mathrm{T}$ cells after activation. This is particularly significant in cancer cells as CTLA-4 has a higher binding affinity to both ligands, compared to CD28. Consequently, it is plausible that the role of the CTLA-4 expressed on the surface of $\mathrm{T}$ cells is to decrease $\mathrm{T}$ cell activation by competing with CD28 for ligand binding as well as active removal of B7.1 and B7.2 from the cell surface of antigen-presenting cells (APCs) (39). It counteracts the activity of the co-stimulatory CD28 upon TCR engagement by the antigen-MHC complex on APCs (40). Upon T cell activation CTLA-4 is translocated via a genetically programed pathway to the cell surface where it competes for binding with CD28. At the cell surface CTLA-4 is stabilized by src kinase-mediated phosphorylation and binds with higher affinity to B7 ligands when compared with CD28. Intracellularly CTLA-4 transduces signals via PP2A and PI3K (41).

$\mathrm{PD}-1$ is an inhibitor of both adaptive and innate immune responses and is more broadly expressed than CTLA-4 on activated T cells, B cells and myeloid cells and its depletion in experimental mice results in the disruption of immune tolerance and in multiple autoimmune features $(42,43)$. The TCR transduces the signal via the PI3K/Akt pathway and positively regulates glucose metabolism, which is reprogrammed during $\mathrm{T}$ cell activation (Figure 1). A negative signal during TCR activation may occur via a ligated PD-1 receptor, which mediates the recruitment of phosphatases, SHP2 (and/or SHP1) to dephosphorylate TCR-proximal molecules and displace the co-stimulatory molecule, CD28, thereby blocking lymphocyte activation. PD-1 ligation also directly inhibits phosphatidylinositol 4,5-isphosphate-3 kinase (PI3K) (44). In the absence of PD-1, TCR signalling leads to Akt activation thereby promoting key cellular activities including glucose metabolism, cytokine production and phosphorylated glycogen synthase kinase-3 (GSK-3 $\beta \_$) associated events which include glycogen synthesis in the liver and in the muscles (45). Hence the inhibition of GSK-3 leads to the development of cancer and other developmental diseases (46). The ligands of PD-1 and CTLA-4 receptors belong to the $\mathrm{B} 7$ family and function by mediating "costimulatory" or "co-inhibitory" signals through the CD28 family of receptors on lymphocytes (47). Engagement of PD-1 by its ligands, PDL-1 and PDL-2, which are expressed on antigen presenting cells downregulates lymphocyte activation (48).

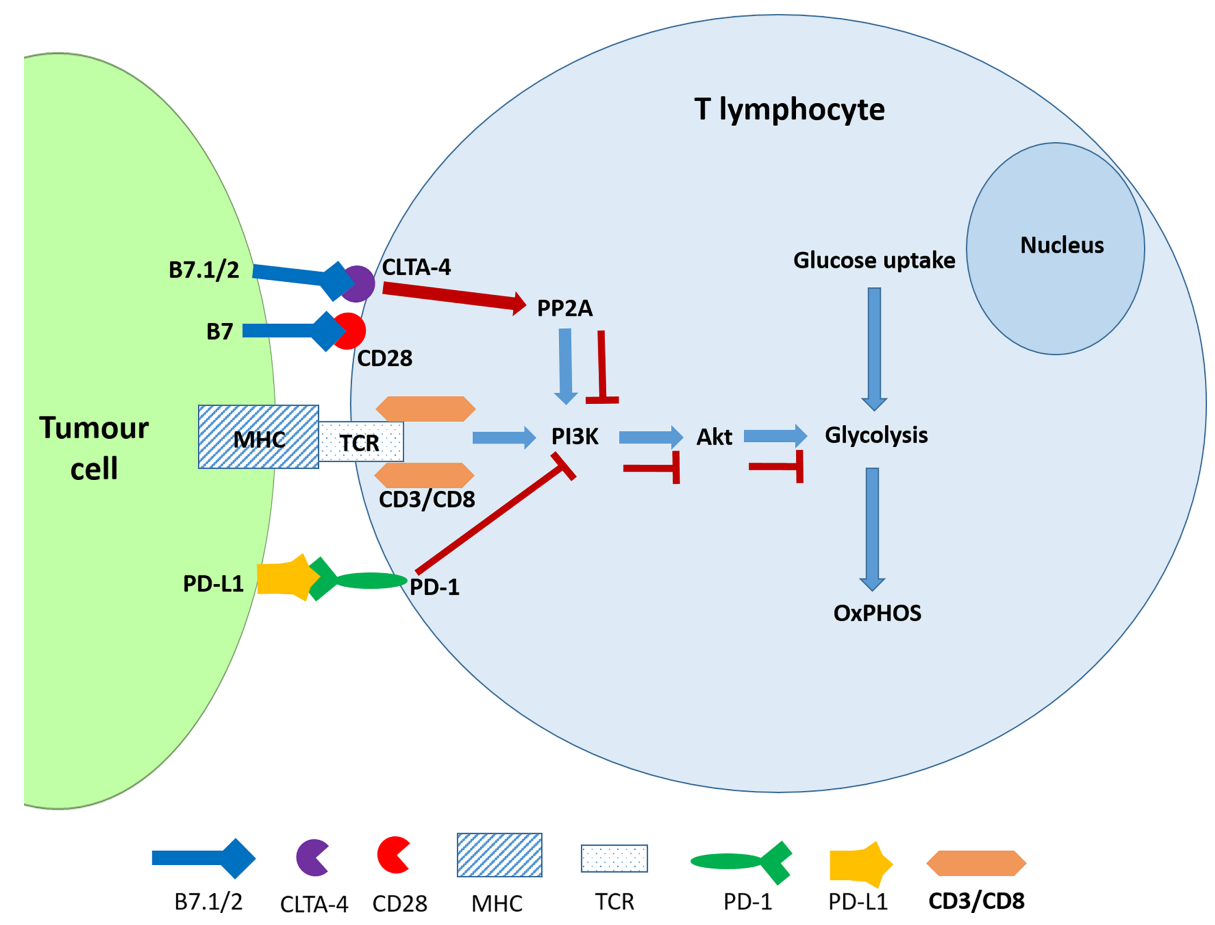

FIGURE 1 | CTLA-4 and PDL-1 ligation interferes with glucose metabolism in activated T cells. The ligation of PD-1 blocks the activation of PI3K and consequently the Akt signalling pathway resulting the inhibition of glycolysis. CTLA-4 accomplishes the same outcome by activating the phosphatase PP2A. 
The evidence has shown that the CTLA- 4 and PD- 1 receptors may inhibit T-cell activation but use different signalling and synergistic pathways. Furthermore, the ligation of these receptors by their physiological ligands leads to the downregulation of glycolysis (45). It is noteworthy that, like cancer cells, activated $\mathrm{T}$ cells also exhibit the Warburg Effect or aerobic glycolysis which is characterised by elevated glycolysis and downregulated oxidative phosphorylation and is driven by mechanistic target of rapamycin (mTOR) signalling (49). The antagonistic effect of checkpoint inhibitors should therefore affect the metabolic reprogramming that would have occurred in activated T cells. However, this has not been specifically investigated according to our knowledge.

It has been shown that $\mathrm{T}$ cell activation requires upregulation of glucose metabolism and that while glucose deprivation does not affect proliferation, it diminishes the effector activities of $\mathrm{T}$ cells thereby driving cancer progression. Alternatively, when glycolysis was inhibited in $\mathrm{CD}^{+} \mathrm{T}$ cell using 2-deoxy-Dglucose (2-DG) in the mouse sarcoma model, interferon gamma (IFN $\gamma$ ) but not Interleukin-2 (IL-2) production was inhibited. Furthermore, a large-scale transcriptional analysis also showed that only $10 \%$ of genes induced by $\mathrm{T}$ cell activation were inhibited by 2 -DG. This small subset of genes comprised those involved in effector functions (50). These observations suggest that the metabolic reprogramming associated with $\mathrm{T}$ cell activation specifies their functional properties However, the impact of glucose metabolic profiles of the tumor microenvironment components on immune checkpoint blockade therapy is still not well understood.

In the solid tumor microenvironment, competition for glucose between cancer cells and tumor infiltrating CD8+ lymphocytes has been shown to result in the suppression of the $\mathrm{T}$ cell metabolic phenotype and effector capacity. Furthermore, it was shown that the glycolytic phenotype of cancer cells suppresses the metabolic programme and effector activities of T cells (51). Importantly, this study showed that antiCTLA-4 and anti-PD-1 antibodies could reverse the antagonistic impact exerted by cancer cells on the TME.

Another question that requires attention is the comparative attractiveness of these receptors as therapeutic targets. Phenotypic differences in PD-1 and CTLA-4 knock-out mice show distinct outcomes that reveal critical features that suggests different responses to therapies that target these receptors. PD$1^{-/-}$mice spontaneously develop lupus-like glomerulonephritis and arthritis. This phenotype is accelerated and characterized with extensive lymphadenopathy when the Fas or lymphoproliferation $\left(l_{p r^{-/}}\right)$mutation is added. On the other hand, transgenic mice with CLTA-4 deficiency rapidly develop lymphoproliferative disease, multi-organ lymphocytic infiltration severe myocarditis and pancreatitis. Moreover, this mutation is lethal within four weeks $(52,53)$. These observations indicate that the blockade of PD-1 might be less toxic when compared to CTLA-4.

\section{IMMUNE CHECKPOINT INHIBITORS}

\section{Mechanism of Inhibitors Targeting CTLA-4}

CTLA-4 functions as a negative regulator of T-cell effector function and therefore presented as an attractive target for cancer therapy. Inhibitors targeting CTLA-4 act by preventing

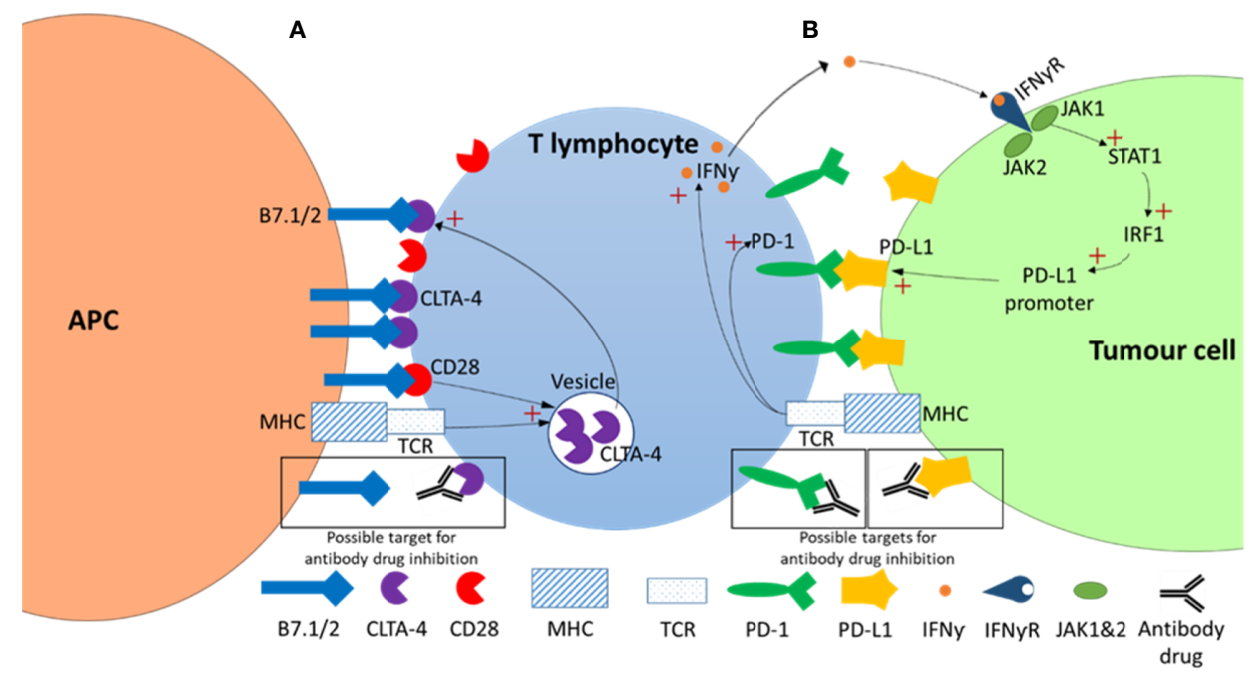

FIGURE 2 | CTLA-4 and PD-1 checkpoint inhibitor pathways. (A) CTLA-4 pathway. In this pathway strong TCR-HMC and CD28-B7 binding signals initiate the exocytosis of the CTLA-4 from the intracellular vesicles to the T cell surface. As CLTA-4 has a higher binding affinity then CD28 for B7, this results in a net negative signal that results in reduced T cell proliferation, survival and a decrease in growth cytokines such as IL-2. (B) In the PD-1/PD-L1 pathway TCR-HMC signalling up regulates both PD-1 and interferon- $\gamma$ (IFNy) expression. The increased of IFNy in the tumor microenvironment activates the signalling pathway of Janus kinase (JAK)/ signal transducer and activator of transcription (STAT) which activates the transcription factor interferon regulatory factor 1 (IRF1), which in turn induces PD-L1 expression. PD-1/PD-L1 interaction results in in a net negative signal and ultimately reduced T cell survival, proliferation and cytotoxic production. Possible antibody drug targets in both pathways are indicated showing antibody-target interaction (within black boxes). 
the binding between CTLA-4 (on T-cells) and B7 ligands (on APCs) (Figure 2). As a result, Treg-associated immune suppression is inhibited and T-cell effector function is promoted, allowing the immune system to mount a response (54-56). An influential clinical trial whereby improved survival rates were seen when patients with unresectable melanomas (stage III/IV) were treated with an anti-CTLA-4 monoclonal antibody ultimately led to the FDA approval of the first immune checkpoint inhibitor, ipilimumab, for cancer therapy (2).

Ipilimumab, marketed as Yervoy ${ }^{\circledR}$ by Bristol-Myers Squibb, is a human IgG1 $\kappa$ anti-CTLA-4 monoclonal antibody. Ipilimumab was originally granted FDA approval for late stage, unresectable melanomas in 2011. It has subsequently been approved for patients with cutaneous melanoma, renal cell carcinoma and metastatic colorectal cancer as shown in Table $\mathbf{1}(3,4,12,57)$. Currently, ipilimumab remains as the only checkpoint inhibitor targeting CTLA-4.

\section{Mechanism of Inhibitors Targeting PD-1}

The interaction between PD-1 (on T-cells) and its ligand, PD-L1 (on APCs) (Figure 2), has an inhibitory effect on T-cell effector activity. The PD-1/PD-L1 pathway therefore represents an additional negative regulator of immune responses and a key mechanism in tumor evasion (58). Inhibitors that target PD-1 act by preventing its binding to PD-L1 (Figure 2). This interferes with the feedback mechanism between T-cells and tumor cells in the tumor microenvironment and consequently restores T-cell effector function enhancing anti-tumor activity (36).

Following the outcome of the CheckMate-037 trial, nivolumab received FDA approval in 2014 for the treatment of unresectable or metastatic melanoma in patients whose cancers had progressed following ipilimumab treatment \pm BRAF inhibitors (2). Nivolumab is a human IgG4 $\kappa$ anti-PD- 1 monoclonal antibody marketed as Opdivo ${ }^{\circledR}$ by Bristol-Myers Squibb. Nivolumab represented the first immune checkpoint inhibitor targeting PD-1 to be granted FDA approval. Its approval was subsequently expanded for the treatment of various cancers including cervical cancer (59), gastric cancer (60), urothelial cancer (8), Hodgkin's lymphoma (6), hepatocellular carcinoma (9), squamous cell carcinoma (13, 61), colorectal cancer (3), non-small cell lung cancer (10), diffuse large B-cell lymphoma (62), renal cell carcinoma (12) and small cell lung cancer $(5,6,8-13,61,63)$ (Table 1).

In 2014 an additional PD-1 inhibitor, pembrolizumab, was granted accelerated approval as an alternative for nivolumab in patients with unresectable or metastatic melanoma based on the results from the NCT01295827 clinical trial $(14,64)$. Pembrolizumab, a humanized IgG4 $\kappa$ anti-PD-1 monoclonal antibody marketed as Keytruda ${ }^{\circledR}$ by Merck, later received expanded approval for the treatment of various cancers including cervical cancer (15), endometrial carcinoma (65), esophageal cancer (26), gastric cancer (18), urothelial cancer (19), Hodgkin's lymphoma (16), hepatocellular carcinoma (21), Merkel cell carcinoma (27), squamous cell carcinoma (25), colorectal cancer $(20,66)$, non-small cell lung cancer (22), diffuse large B-cell lymphoma (17), renal cell carcinoma (24) and small cell lung cancer (15-22, 24-27, 66, 67).
Cemiplimab, a human IgG4 $\kappa$ anti-PD-1 monoclonal antibody marketed as Libtayo ${ }^{\circledR}$ by Sanofi, is the most recent immune checkpoint inhibitor to be given FDA approval. In 2018, cemiplimab was approved for the treatment of metastatic cutaneous squamous cell carcinoma (28).

\section{Mechanism of Inhibitors Targeting PD-L1}

Similar to inhibitors targeting PD-1, PD-L1 inhibitors aim to disrupt the interaction between $\mathrm{PD}-1$ and $\mathrm{PD}-\mathrm{L} 1$ in the tumor microenvironment. Inhibiting PD-1/PD-L1 results in the stimulation of T-cell anti-tumor activity as described previously $(36,68)$.

The first PD-L1 inhibitor granted FDA approval was Atezolizumab in 2016. Atezolizumab is a human IgG1א antiPD-L1 monoclonal antibody marketed as Tecentriq ${ }^{\circledR}$, by Genentech and Roche. The mAb was found to be effective for the treatment of metastatic urothelial carcinoma following platinum chemotherapy (69). The therapy was subsequently approved for treatment of metastatic non-small-cell lung carcinoma (NSCLC) (29) and advanced urothelial carcinoma in patients that are ineligible for chemotherapy (19). In 2018, Atezolizumab was further approved for the treatment of metastatic NSCLC in combination with chemotherapy and bevacizumab, a mAb targeting VEGF (70). Following the first combinational therapy, Atezolizumab was subsequently approved in combination with paclixatel (71) and chemotherapy (72) for the treatment of metastatic triple negative breast cancer (TNBC) and small cell lung cancer (SCLC), respectively.

Avelumab, marketed as Bavencio ${ }^{\circledR}$ by Merck/Pfizer, is a human IgG1 $\lambda$ monoclonal antibody that targets PD-L1. Avelumab was first approved by the FDA for the treatment of Merkel cell carcinoma in 2017 (30). Following its first approval, avelumab was granted further approval for the treatment of locally advanced and metastatic urothelial carcinoma (32). In 2019, avelumab was approved for the treatment of advanced renal cell carcinoma (RCC) in combination with axitinib, a tyrosine kinase inhibitor (31).

Another PD-L1 inhibitor, durvalumab, was granted FDA approval in 2017 for the treatment of advanced bladder cancer in patients that previously did not respond to chemotherapy or ineligible for the treatment (33). Durvalumab is a humanized IgG1 $\kappa$ anti-PD-L1 monoclonal antibody marketed as Imfinzi ${ }^{\circledR}$ by AstraZeneca. In 2019, the immune checkpoint inhibitor was approved for the treatment of unresectable stage III NSCLC (34).

\section{The Mechanism of Next Generation Inhibitors Targeting LAG-3, TIM-3, TIGIT, VISTA and B7-H3}

CTLA-4, PD-1 and PD-L1 are the most broadly studied checkpoints. However, given the success seen with previous checkpoint inhibitors, new inhibitory pathways and next generation inhibitors targeting LAG-3, TIM-3, TIGIT, VISTA and $\mathrm{B} 7-\mathrm{H} 3$ are being investigated. The mechanisms of these checkpoints as well as inhibitors that are currently in clinical trials will be described briefly.

Lymphocyte activation gene-3 (LAG-3 or CD223) is a membrane receptor constitutively expressed by $\mathrm{T}$ cells and natural killer cells. LAG-3 interacts with MHC class II resulting in 
a negative regulatory effect over $\mathrm{T}$ cell function (73). This interaction normally prevents tissue damage and autoimmunity, however, tumor-infiltrating lymphocytes (TILs) found in the TME upregulates LAG-3 thereby promoting cell dysfunction, immune exhaustion and favorable conditions for tumor growth (74). Thus, disrupting the LAG-3/MCH II interaction with blockade therapy should encourage immune activation and anti-tumor responses.

T cell immunoglobulin-3 (TIM-3) is an immune checkpoint expressed on numerous cells including effector $\mathrm{T}$ cells, B cells, Tregs, macrophages and natural killer cells (75). Its main ligand is galactine-9, but it is also known to interact with phosphatidyl serine and carcinoembryonic antigen-related cell adhesion molecule (CEACAM) $(76,77)$. TIM-3 functions as a direct negative regulator of $\mathrm{T}$ cells. Interaction with its various ligands results in $\mathrm{T}$ cell exhaustion as well as expansion of myeloid-derived suppressor cells (MDSCs) in the TME creating favorable conditions for tumor growth. Not surprisingly, TIM-3 levels have been found elevated in several malignancies. Blockade of TIM-3 decreases MDSCs while increasing $\mathrm{T}$ cell proliferation and cytokine production leading to anti-tumor activity (78). However, there has been some concern over TIM-3 blockade. Considering its role in immune responses against listeria and mycobacteria, inhibiting TIM-3 may result in an increased risk of these infections (79). Nevertheless, antibodies targeting this receptor have proceeded to clinical trials.

$\mathrm{T}$ cell immunoglobulin and ITIM domain (TIGIT) is a receptor part of the CD28 family and is expressed by $\mathrm{T}$ cells and natural killer cells (80). CD155 and CD112 are ligands that interact with TIGIT to bring about immunosuppressive effects (81). Studies have shown that tumor-infiltrating lymphocytes have elevated levels of TIGIT co-expressed with PD-1, LAG-3 and TIM-3 suggesting a role in tumor progression. Dual blockade of TIGIT and either TIM-3 or PD-1 has revealed an anti-tumor mechanism through immune cell proliferation, cytokine release and reversal of $\mathrm{T}$ cell exhaustion (82).

$\mathrm{V}$-domain Ig suppressor of $\mathrm{T}$ cell activation (VISTA) is an unusual immune checkpoint with dual function as an inhibitory and stimulatory molecule (83). VISTA, expressed as a receptor on T cells, interacts with VSIG-3 on tumor cells to suppress T cell activation, proliferation and production of cytokines promoting tumor progression. This co-inhibitory pathway therefore presented as an alternative strategy for blockade therapy (84). Although most studies have described the inhibitory effects of VISTA on immune responses, other studies have demonstrated that VISTA can act as a ligand expressed on APCs allowing for immune activation. Regardless, blockade of VISTA seemed to enhance $\mathrm{T}$ cell infiltration and reduce myeloid suppressive cells proving to be an effective anti-tumor strategy $(85,86)$.

$\mathrm{B} 7$ homolog $3(\mathrm{~B} 7-\mathrm{H} 3)$ is a transmembrane protein found on various solid organs as well as immune cells such as APCs, T cells, B cells and natural killer cells. Although the exact ligand remains unknown, B7-H3 is believed to interact with the CD28 receptor family (87). This interaction prevents $\mathrm{T}$ cell activation, proliferation, cytokine production and appears to enhance cancer aggressiveness. B7-H3 blockade promotes $\mathrm{T}$ cell activation, cytokine release and cytotoxic activity. Moreover, it has been associated with fewer immune-related adverse events (irAEs) due to the lower expression of B7-H3 in normal tissues as opposed to the TME allowing for localised effects (88).

TABLE 2 | Next generation immune checkpoint inhibitors.

\begin{tabular}{|c|c|c|c|c|}
\hline Target & Binding partner & Drugs & Trial stage & References \\
\hline \multirow[t]{10}{*}{ LAG-3 } & $\mathrm{MHC}-\|$ & Eftilagimod alpha (Immutep) & $\mathrm{l} / \mathrm{II}$ & (89) \\
\hline & & Relatimab (Bristol Myers Squibb) & $\|/\| \|$ & \\
\hline & & Ieramilimab (Novartis) & $\|$ & \\
\hline & & Favezelimab (Merck) & $|/| \mid$ & \\
\hline & & Fianlimab (Regeneron) & l & \\
\hline & & Encelimab (AnaptysBio/GlaxoSmithKline) & I & \\
\hline & & Miptenalimab (Boehringer Ingelheim) & I & \\
\hline & & Sym 022 (Symphogen) & 1 & \\
\hline & & FS118 (F-star) & I & \\
\hline & & Tebotelimab (MacroGenics) & 1 & \\
\hline \multirow[t]{7}{*}{ TIM-3 } & Galactine-9, phosphatidyl serine, CEACAM & TSR-022 (GlaxoSmithKline) & I & (75) \\
\hline & & Sabatolimab (Novartis) & $|/| \mid$ & \\
\hline & & Sym 023 (Symphogen) & 1 & \\
\hline & & INCAGN 2390 (Incyte Corporation) & 1 & \\
\hline & & LY3321367 (Eli Lilly and Company) & $|/| \mid$ & \\
\hline & & BMS-986258 (Bristol Myers Squibb) & $\mid / I I$ & \\
\hline & & SHR-1702 (Jiangsu HengRui) & 1 & \\
\hline \multirow[t]{5}{*}{ TIGIT } & CD155, CD112 & Vibostolimab (Merck) & III & $(80)$ \\
\hline & & Etigilimab (OncoMed Pharmaceuticals) & I & \\
\hline & & Tiragolumab (Genentech) & $\|$ & \\
\hline & & BMS-986207 (Bristol Myers Squibb) & $|/| \mid$ & \\
\hline & & Domvanalimab (Arcus Biosciences) & 1 & \\
\hline \multirow[t]{2}{*}{ VISTA } & VSIG-3 & JNJ-61610588 (Johnson \& Johnson) & 1 & $(90)$ \\
\hline & & Cl-8993 (Curis Inc) & & \\
\hline \multirow[t]{3}{*}{ B7-H3 } & Unknown & Enoblituzumab (MacroGenics) & $\|$ & (91) \\
\hline & & ${ }^{131}$ I-omburtamab (Y-mAbs Therapeutics) & $\|/\| \|$ & \\
\hline & & ${ }^{124}$ I-omburtamab (Y-mAbs Therapeutics) & I & \\
\hline
\end{tabular}


Drugs targeting LAG-3, TIM-3, TIGIT, VISTA and B7-H3 that are currently in clinical trials are listed in Table 2. Apart from these immune checkpoints, drugs associated with inhibitory targets beyond traditional immune checkpoints which lead to indirect repercussions on T-cell effect are also being investigated as next generation inhibitors. This has been reviewed in detail elsewhere (92).

\section{Challenges Associated With Immune Checkpoint Inhibitors}

Immune checkpoint blockade (ICB) therapy has become one of the most successful cancer treatment strategies developed to date. A pooled meta-analysis study evaluating the long-term survival of 1861 advanced melanoma patients, receiving ipilimumab therapy, estimated a 3 -year survival rate of $22 \%$ (93). The significance of these results is highlighted when compared to melanoma patients treated with dacarbazine, a chemotherapeutic agent, and 3-year survival rates were only $12.2 \%$ (14). In comparison to chemotherapeutics, ICB has allowed better disease control and outcomes for some patients. Accordingly, immunotherapy is now at the forefront for management of various malignancies. But despite the remarkable progress, ICB is challenged by low response rates, immune-related adverse events (irAEs) and resistance to treatment.

Response rates are known to vary depending on the type of malignancy. While excellent response rates are seen in Hodgkin's lymphoma and melanomas which range from 40-70\%, response rates in most other diseases is limited to only $10-25 \%$ (94). The unfortunate reality is that majority of patients do not experience any benefit from treatment with immune checkpoint inhibitors, and those that do, are likely to experience irAEs. Immune-related adverse events are caused from non-specific activation of the immune system resulting in immune responses that target selfantigens. ICB therapy most frequently results in dermatological irAEs such as pruritis and mucositis $(68 \%$ of patients on ipilimumab therapy). Gastrointestinal distress and immune mediated colitis have also been reported in $40 \%$ of patients on ipilimumab therapy. Less common irAEs include endocrinopathies, hepatotoxicity, pneumonitis, renal toxicity, pancreatitis, neurotoxicity, cardiovascular toxicity and hematological abnormalities $(95,96)$. Inhibition of CTLA-4 has been associated with a higher frequency and severity of irAES than checkpoint inhibitors targeting the PD-1/PD-L1 axis (97). Although irAEs can be managed, they often lead to the discontinuation of treatment in some patients. Lastly, a crucial limitation of ICB therapy is related to resistance. Patients that fail to respond to treatment (innate resistance) and patients that respond initially but eventually develop disease progression (acquired resistance) will be discussed further.

\section{Mechanisms of Resistance to Immune Checkpoint Inhibitors}

Immune checkpoint inhibitors targeting the CTLA-4, PD-1, and its ligand PD-L1 have been successful at inducing an anti-tumor immune response in several cancers (98). Ipilimumab was the first agent in the class of immune checkpoint inhibitors (ICIs) to be granted FDA approval for the treatment of metastatic melanoma in 2011 albeit with significant immune-related adverse events (irAEs) which needed to be addressed (99). Since then, diverse ICIs targeting the PD-1 (cemiplimab, nivolumab and pembrolizumab), and PD-L1 (atezolizumab, avelumab and durvalumab) have been granted FDA approval for the treatment of various cancers. To date there are several other ICIs currently in clinical trials. Although these agents have been successful at maintaining a sustained response in some cancer patients, the overall response is usually low, and some patients develop resistance over time (100). Resistance to ICIs may be innate (primary) or acquired (secondary). Resistance can also be classified as intrinsic or extrinsic to tumors. In intrinsic resistance, tumor cells modify processes associated with DNA damage response, cell signalling pathways and immune recognition. Extrinsic resistance occurs external to tumor cells and is facilitated by interactions of immune cells and nonimmunological mechanisms in the tumor microenvironment (101-105).

Successful blockade of CTLA-4 and PD-1/PD-L1 in tumors results in reactivation and proliferation of T-cells. Activation of T-cells is dependent on the successful presentation of tumor antigens by APCs and the recognition of these antigens by $\mathrm{MHC}$ I and/or II. T-cells recognise the MHC-bound antigens and stimulate T-cell proliferation through co-stimulatory factors described previously (106). Both CTLA-4 and PD-1/PD-L1 pathways play a significant role in tumor evasion through down regulation of the immune response. Tumors evolve mechanisms to evade immune checkpoint blockade, thereby reducing the effectiveness of ICI therapy. In the following sections, we describe the various mechanisms that govern the evasion of $\mathrm{T}$ cell cytotoxicity by tumor cells following treatment with ICIs.

\section{INNATE AND ACQUIRED RESISTANCE}

\section{Tumor Neoantigens}

Innate or primary resistance is observed in tumors that have never responded to the initial treatment with ICIs (104). The most notable trigger of intrinsic resistance relates to genetic and epigenetic alterations that influence tumor neoantigen presentation, structure, and processing $(106,107)$. Neoantigens are peptides produced in the tumor because of somatic mutations that occur in cancer cells (108). The tumor neoantigen repertoire is crucial for the activation of an immune response and recruitment of effector T-cells to the tumor. Tumors with high mutational rates are typically responsive to ICI therapy compared to tumors with low tumor mutational burden (TMB) apart from renal cell carcinomas (66, 109-111).

Emerging evidence indicates that some tumors lose or down regulate generation of neoantigens required to illicit an immune response and therefore the tumor escapes T-cell cytotoxicity (63). Anagnostou and colleagues $(63,82)$ assessed biopsies of relapsed NSLC patients and observed a downregulation of key 
tumor antigens indicative of an anti-PD-1 and anti-CTLA-4 resistance. Efficacy of anti-PD-1 inhibitors is dependent on the availability of tumor antigen specific T-cells in the tumor microenvironment and the upregulation of PD-1 in effector Tcells and PD-L1 in tumor cells. This requires tumors to present specific antigens that are different from the original tumor cells. Without these antigens, the immune checkpoint blockade is attenuated.

In addition to tumor neoantigen downregulation, tumors escape immunosuppression through alteration of the antigen presentation machinery. Dendritic cells (DCs) initiate an immune response through uptake and presentation of tumor antigens to activate naïve CD4 and CD8 T cells $(112,113)$. DCs activate the CD8 $\mathrm{T}$ cells in a process called cross priming where antigens are presented to CD8 $\mathrm{T}$ cells via $\mathrm{MCH}$ I to generate an anti-tumor CD8 T cell response (114). Cross priming of tumor specific CD8 $\mathrm{T}$ cells is very important in initiation and stabilisation of the anti tumor immune response. Deficiencies in $\mathrm{T}$ cell priming mechanism have been shown to contribute unresponsiveness to immune checkpoint inhibition therapy (115). The TME plays a major role in the transportation of effector CD8 T cells to tumors and alterations in the TME therefore affect the anti-tumor response. In particular, the presence of tumor derived inhibitory molecules such as interleukin (IL-6, 10), transforming growth factor beta (TGF $\beta$ ) and VEGF produced by the tumor negatively impact the growth, maturation and differentiation of DCs (116, 117). These molecules are usually secreted by myeloid derived suppressor cells (MDSCs), tumor-associated macrophages (TAMs) and regulator $\mathrm{T}$ cells (Tregs) which are discussed in subsequent sections.

\section{Dysfunctional Major Histocompatibility Complex Molecules}

Alterations in the structure of MHC-I/II and the antigen presenting machinery, beta 2 microglobulin (B2M), prevents the identification and presentation of tumor antigens (118). The MHC class I pathway is responsible for antigen presentation and any defects in the genes associated with MHC-1 pathways such as the HLA class I and the B2M gene affect antigen presentation and ultimately immune response (119). This phenomenon has been observed in several tumors with $B 2 M$ mutations and more specifically the loss of heterozygosity $(\mathrm{LOH})$ of the $B 2 M$ gene. Indeed, these modifications have been observed in various tumor tissues and have been associated with resistance to anti-PD-1/PD-L1 and anti-CTLA-4 immune checkpoint inhibitors (120-122).

\section{Inadequate Anti-Tumor T-Cell Effector Function}

Interestingly, mutations in the JAK1 and JAK2 pathways have also been associated with resistance to ICI treatment $(123,124)$. JAK1/2 are key intermediates in the interferon signaling pathways. Since the interferon pathway (INF) is particularly involved in the upregulation of PD-L1 expression, blockade of the PD-1/PD-L1 is likely ineffective in tumors with alterations in the interferon pathway. This is suggestive of an alternate mechanism of immune evasion in tumor cells other than PD1/PD-L1 upregulation (125). Moreover, Gao and colleagues reported anti-CTLA-4 resistance in tumors with LOH in many genes associated with the INF $\gamma$ pathway (126). It has been shown in melanoma that the interferon-gamma-JAK1/JAK2-STAT1/ STAT2/STAT3-IRF1 signaling cassettes primarily regulates PDL1 expression on the cancer cell, through IRF1 binding to its promoter. This establishes PD-L1 as an interferon- $\gamma$ immediate response gene. Upon tumor antigen recognition in the context of the MHC, the $\mathrm{T}$ cell releases interferon gamma that binds to its receptors on the cancer cell. This is followed by the transduction of a signal via the JAK/STAT pathway, culminating in the activation of the paralogous the PD-L1 and PD-L2 genes of the tumor cell (Figure 2). In this way interferon gamma can play a critical role in negative regulation of $\mathrm{T}$ cell activation through the expression of $\mathrm{PD}-1$ receptors on the tumor cell. Immune checkpoint blockade therapy acts by blocking PD-1/PD-L1/2 interaction thereby restoring $\mathrm{T}$ cell activation and anti-tumor activity. The evidence shows that dysregulation of this pathway in the tumor cell produces resistance to PD-1 based ICB therapy. It was shown that loss of function mutations in $\mathrm{Ak} 1 / 2$ and subsequent lack of PD-L1 expression led to primary resistance to anti-PD-1 antibody therapy $(123,127)$. Similar interferon signalling dependent resistance has been demonstrated with the anti-CTLA-4 therapy, ipilimumab (126). Though studies on delayed relapses after anti-PD-1 therapy, the interferon- $\gamma$ signalling pathway has been shown to be associated with acquired immunity to anti-PD-1 immune blockade therapy (124). The inhibitory CTLA-4 is essentially an intracellular molecule whose trafficking from intracellular vesicles to the to the cell surface is tightly regulated to maintain an optimal balance with stimulatory molecules (41).

\section{T-Cell Exhaustion}

$\mathrm{T}$ cell exhaustion is a phenomenon that was first described in mice with chronic viral infections, and thereafter observed in humans with chronic viral infections and cancer (42, 128-131). More recently, however, it has been linked to resistance in ICB therapy. Exhausted T cells in the tumor microenvironment have been shown to progressively lose their functional capacity to proliferate, produce effector cytokines and lyse upon chronic antigen exposure $(130,131)$. While numerous pathways may individually influence $\mathrm{T}$ cell exhaustion, the PD-1/PD-L1 checkpoint pathway partly contributes to $\mathrm{T}$ cell exhaustion. In exhausted T cells, PD-1 expression is driven by demethylation of its promoter. The stability of this epigenetic mechanism blocks long-term effector function or memory development by $\mathrm{T}$ cells following ICB therapy, potentially explaining disease relapse in patients treated with PD-1/PD-L1 checkpoint inhibitors (132134). Moreover, studies have reported that $\mathrm{T}$ cell exhaustion in acquired resistance is a consequence of the up-regulation of other checkpoint inhibitors such as TIM3, LAG3 and VISTA following checkpoint blockade $(120,135,136)$. The exact mechanisms leading to $\mathrm{T}$ cell exhaustion following ICB therapy is largely unclear and further studies are required to validate the dysfunctional $\mathrm{T}$ cell states and their contribution to resistance. 


\section{The Tumor Microenvironment (TME)}

The TME contains various types of cells that play a significant role in the promotion or inhibition of the tumor. The cell types include regulatory $\mathrm{T}$-cells (Treg cells), myeloid derived suppressor cells (MDSCs), cancer-associated adipocytes, fibroblasts and endothelial cells; and tumor-associated macrophages (TAMs) (137). Through producing various molecules, Tregs, MDSCs, TAMs and tumor-associated stromal cells inhibit the anti-tumor $\mathrm{T}$-cell response and maintain an immune tolerant tumor that attenuates the effectiveness of ICIs $(138,139)$. Foxp3 Treg cells, are mainly produced by the thymus as a functionally mature and distinct $\mathrm{T}$ cell subpopulation, whose function is to maintain self-tolerance after an immunological response or activation (140).

Treg cells produce immunosuppressive molecules including transforming growth factor- $\beta$ (TGF- $\beta$ ) and interleukin-10 (IL10) which typically interfere with the activation, proliferation and survival of effector T-cells (141). Additionally, Tregs also upregulate the expression of immune checkpoints such as CTLA-4, PD-1 and others (142). The effectiveness of antiCTLA-4 mAb is dependent on decreasing Treg cells in tumors via antibody-dependent cytotoxicity but this mechanism does not affect the activation of CTLA-4 (143). For this reason, antiCTLA-4 alone selectively depletes Treg cells permitting immunosuppression stimulated by remaining Treg cells (138, 144). Several animal studies have shown a connection between amount of Treg cells in the TME and enhanced antitumor immunity $(145,146)$. Studies in cancer patients treated with anti-CTLA-4 therapy revealed better response to treatment in patients with a low ratio of Treg cells compared to Teff cells in the TME $(140,147)$. Recruitment of Tregs in the TME relies upon metabolic processes associated with lipid metabolism. A study by Pacella and colleagues (2018) showed that both increased glycose and oxidative metabolism influenced Tregs expansion by fueling fatty acid (FA) synthesis (148).

Tumor-associated macrophages (TAMs) support tumor growth through the expression of PD-L1 ligand and $\mathrm{Na} / \mathrm{H}$ exchanger isoform 1 (NHE1) $(149,150)$. NHE1 maintains the alkaline intracellular $\mathrm{pH}$ of glioma cells, a driving force of glycolytic metabolism exploited by cancer cells in a process called Warburg Effect $(151,152)$. Moreover, TAMs are involved in the production of cytokines such as transforming growth factor (TGF- $\beta$ ) and vascular growth factor (VEGF-A) implicated in tumor evasion $(153,154)$. Since TAMs can regulate the production of pro-inflammatory and immune response inhibitory molecules, anti-PD-L1 inhibition alone is not sufficient for prolonged suppression of the tumor.

Myeloid-derived suppressor cells (MDSCs) alter the function of CD8+ $\mathrm{T}$ cells through numerous mechanisms including a (i) decrease in arginine and cysteine production in the TME, (ii) reduced transport of $\mathrm{T}$ cells into the lymph node and tumor, (iii) production of free radicals that ultimately block TCR and IL2 signaling, inducing $\mathrm{T}$ cell death and expansion of Tregs (155). Like TAMs, MDSCs may be induced by tumor-derived factors such as TGF- $\beta$, ILs 1, 6, 10 and VEGF-A. MDSCs cells have been shown to also express immune checkpoint PD-L1, further contributing to immunosuppression in mice models (156). The manifestation of MDSCs was associated with poor prognosis in metastatic melanoma patients treated with anti-CTLA-4 (ipillimumab) $(157,158)$.

\section{Metabolic Reprogramming in the TME}

Cancer cells tend to accumulate metabolic alterations that allow them to utilize eccentric sources of nutrients to support cancer cell proliferation and deprive antitumor immune cells of nutrients within the tumor microenvironment. Because tumors are heterogeneous in nature, they often have complex metabolic patterns. The first evidence of variations in nutrient metabolism observed in cancer and normal cells was reported in the 1920s by Warburg and colleagues (159). They observed a marked increase in glucose metabolism in cancer cells compared to nonproliferating normal cells; and the preference of glycolysis over oxidative phosphorylation (OXPHOS) even in the presence of oxygen and functional mitochondria. The observed phenomenon was later termed the "Warburg Effect" (159). This observation was further corroborated in a variety of tumors associated with poor prognosis (160). Even though there are other metabolic processes and molecules governing tumor resistance, we will focus on the metabolism of glucose in the TME and its impact on tumor progression and antitumor immune escape.

The high demand for glucose in cancer cells within the TME starves immune cells resulting in poor antitumor immune response (51). When $\mathrm{T}$ cells are inactive, they largely rely on OXPHOS and fatty acid oxidation (FAO) to support their needs. Once $\mathrm{T}$ cells are activated through binding of costimulatory receptors such as CD28, T cells alter their metabolism to support $\mathrm{T}$-cell proliferation and $\mathrm{T}$ cell effector $\left(\mathrm{T}_{\text {eff }}\right)$ functions (161). The CD28 co-stimulation drives the activation of the PI3K/AKT pathways and glycolytic flux $(162,163)$. The dramatic increase in glycolysis in T cells is essential for T-cell growth, division, and differentiation into cytotoxic $\mathrm{T}$ cells (164). Since glucose is required by tumors and is essential to support immune cell growth, differentiation and function, its metabolism within the TME affects the function of immune cells infiltrating the TME (165). The competition for glucose metabolism within the TME deprives tumor infiltrating lymphocytes (TIL) of glucose resulting in their exhaustion and tumor immune escape (166).

In addition, the preference for aerobic glycolysis in tumors increases the levels of lactic acid in the TME resulting in an acidic environment that further supports the growth of tumors whilst inhibiting immune cell function within the TME. Indeed Muller and colleagues (2000) showed that the activation and function of tumor infiltrating immune cells (IL-2) was significantly perturbed in acidic conditions. Both the stimulated and unstimulated human PMBCs were unable to kill tumor cells after three days of culture in an acidic culture environment of $\mathrm{pH}$ 6.5 (167). This finding was further supported by Calcinotto and colleagues (168) using mice models and human tumor cell lines. Using in vitro and in vivo models, Calcinotto and colleagues revealed that the acidic microenvironment not only affected the function of effector cells but also induction of T-cell anergy (168). 
In addition to interfering with immune cell activation and function, acidic $\mathrm{pH}$ in the microenvironment also upregulates the expression of CTLA-4 on T lymphocytes, therefore intensifying antitumor resistance (169).

Besides the increased uptake of glucose by tumor cells; competitive uptake of other metabolites, amino acids (glutamine, arginine, tryptophan) and growth factors by tumor cells also affects the function of immune cells $(51,165)$.

Amino acids are protein building blocks, the high availability of amino acids in the TME is essential for tumor growth. At the same time, amino acids are essential for immune cells differentiation and development of their antitumor effector cells (170). For example, glutamine powers the tricarboxylic acid (TCA) cycle via glutaminolysis, to provide metabolic intermediates that serve as building blocks for lipids, proteins, and nucleic acids, which are necessary for cancer cell proliferation. Interestingly, the metabolic pathway used by the tumors has been shown to be essential for $\mathrm{T}$ cell activation and proliferation $(171,172)$.

There are several studies that have investigated the impact of targeting different metabolic pathways to assist the immune checkpoint inhibition or circumvent resistance. The metabolic dependencies between tumor and immune cells in the TME make it challenging to obtain antitumor effects with drugs targeting metabolic processes (170). Targeting enhanced glycolytic activity of tumors through inhibition of glycolysis regulatory enzymes or via application of competitive glucose analogs has been shown to promote $\mathrm{T}$ - cell proliferation and function $(166,173)$. Various studies have shown that the blockade of immune checkpoints (PD/PD-L1 and CTLA-4) rescues TILs from tumor-induced glucose restrictions and restores glycolysis in T-cells.

\section{STRATEGIES TO OVERCOME RESISTANCE TO IMMUNE CHECKPOINT BLOCKADE THERAPY}

When looking at patients that experience resistance, it is helpful to define them into two broad categories, firstly are the ones with innate resistance, who never respond to the immune checkpoint therapy (ICT) and secondly are the ones who have acquired resistance, who respond positively to treatment at first, but then build up a resistance resulting in the treatment becoming ineffective over time (102). Studies have found that tumors that are infiltrated by $\mathrm{T}$ cells and therefore that have initiated an inflammatory response as well as have a higher mutational burden have a better response to ICT then tumors that do not, this is especially important when looking at potential strategies to combat resistance to ICI (174).

An essential aspect to combating ICT resistance requires a deeper understanding of the exact mechanisms involved, down to an individual level, so that therapies can be adapted to the tumor microenvironment. To overcome resistance against a single checkpoint inhibitor target, combinational therapies have been conducted. Multiple combinations of different therapies have been successfully tried with the most promising combination therapies including ICT paired with (i) other checkpoint inhibitors, with a combination of anti-PD-1 and anti-CTLA-4 already having been approved for multiple cancers as they have been shown to improve T-cell activation and decrease T-cell exhaustion (175) and combinations with next generation ICT such as anti-LAG and anti-TIGHT showing similar positive results (176). (ii) Immunotherapeutic agents such as cancer vaccines and oncolytic virus therapy which can improve antigen presentation and recognition and $\mathrm{T}$ cell infiltration $(177,178)$. (iii) Removal of co-inhibitory signals and activation of co-stimulatory signals which can amplify $\mathrm{T}$ cell activation and T cell cytotoxicity (179). (iv) DNA damaging therapies such as chemotherapy or radiation which has been seen to increase antigen presentation, pro-inflammatory cytokines and activation of dendritic cells, to stimulate the presentation of neoantigens in non-inflamed, non T cell infiltrated tumor cells (180) and (v) more targeted therapies including monoclonal antibodies and tyrosine kinase inhibitors which have been seen to enhance antitumor immunity, increase $\mathrm{T}$ cell infiltration and decrease $\mathrm{T}$ cell exhaustion (181).

In addition to these, epigenetic modifications within cancer cell DNA can impact the presentation and processing of antigens, which can promote immune evasion, therefore, demethylating agents may also increase the response to combination ICT treatment as they have been seen to elicit an immunostimulatory response, upregulation of cytokine production as well antigen presentation and inhibition of $\mathrm{T}$ regulation cells (182). Interestingly a link has been reported between the gut microbiome and response to ICT, where mice suffering from sarcomas that were fed with a germ-free diet, had a very poor response to CTLA-4 blockade therapy. This was further supported when their response was restored upon being fed with Bacteroides fragilis (183). This has since been concluded in a number of studies that demonstrate that gut microbiome can affect a person's response to ICT treatment (184).

Lastly biomarkers have also become a topic of interest in helping overcome resistance as they can be investigated to estimate the predicted response of an individual to treatment. Biomarkers of particular interest include PD-L1 expression, tumor mutation burden (TMB), microsatellite instability-high (MSI-H) or mismatch repair (MMR) deficiency, IFN- $\gamma$ signalling and T-cell infiltration (185). The only predictive biomarker that has been approved to date is PD-L1 expression using immunohistochemistry (IHC), in which higher expression correlates to a positive response to ICT and fewer side effects observed (186). However, because the detection of PD-L1 relies on antibody staining techniques, this creates inconsistencies in the accuracy of results and therefore its predictive value (187). $\mathrm{TMB}$ as a potential biomarker looks for somatic mutations via DNA sequencing, with an increased number of mutations resulting in higher neoantigen production and therefore a positive response to ICT, however not all mutations and neoantigens correlate equally towards a positive response (188). Defective DNA mismatch repair (MMR) can lead to 
high microsatellite instability (MSI-H), and MSI-H is associated with higher neoantigen production by tumors and therefore a stronger immune response and better response to ICT. MSI has been argued to be the most accurate biomarker predictor (189).

Activation of IFN- $\gamma$ signalling can be used as a predictive biomarker as studies have found loss of function mutations or gene knockdowns in this pathway result in resistance to ICT treatment $(7,23,182)$. IFN- $\gamma$ signalling up regulates the major histocompatibility complex II as well as antigen presenting cells (APCs) and increases PD-L1 expression, however on the other hand studies have found that chronic IFN- $\gamma$ signalling can lead to acquired resistance, therefore it seems early IFN- $\gamma$ signalling may predict positive response to ICT but once resistance is acquired, continued IFN- $\gamma$ signalling can predict further resistance (190). Lastly decreased $\mathrm{T}$ cell infiltration and a lack of an inflammatory response has been reported to be linked to poorer prognosis and is therefore predictive of a low response to ICT (191).

\section{FUTURE DIRECTIONS}

This review examined the successes and failures of immune checkpoint inhibitors (ICIs) and focused on resistance mechanisms. Although ICIs have produced unmatched and durable clinical responses in some cases, this revolutionary strategy has not succeeded in most patients. The limited application of this revolutionary cancer treatment strategy is the most critical matter and is a subject of intense investigation. Critically, it is not possible to predict who is likely or unlikely to benefit from ICI therapy. Towards this end, the discovery of biomarkers is ongoing and is expected to allow personalized treatment approaches. Also, the immune-related adverse effects present a difficult challenge because they are unique and unlike adverse effects often seen with traditional treatments. Although irAEs are usually low-grade and reversible, they can also cause permanent disorders and affect any organ. Another challenge to ICI treatment is that poorly understood primary or secondary resistance limits treatment outcomes. The enormous impact of the tumor microenvironment on carcinogens adds a chaotic dimension to the study of cancer as the TME is a dynamic system and pliable. Presumably, there are deterministic laws or logical patterns that govern the apparent random environment. With the advances in artificial intelligence and high-throughput data,

\section{REFERENCES}

1. Nurieva R, Thomas S, Nguyen T, Martin-Orozco N, Wang Y, Kaja M-K, et al. T-Cell Tolerance or Function Is Determined by Combinatorial Costimulatory Signals. EMBO J (2006) 25(11):2623-33. doi: 10.1038/ sj.emboj.7601146

2. Hodi FS, O’Day SJ, McDermott DF, Weber RW, Sosman JA, Haanen JB, et al. Improved Survival With Ipilimumab in Patients With Metastatic Melanoma. New Engl J Med (2010) 363(8):711-23. doi: 10.1056/NEJMoa1003466

3. Overman MJ, McDermott R, Leach JL, Lonardi S, Lenz H-J, Morse MA, et al. Nivolumab in Patients With Metastatic DNA Mismatch RepairDeficient or Microsatellite Instability-High Colorectal Cancer (Checkmate 142): An Open-Label, Multicentre, Phase 2 Study. Lancet Oncol (2017) 18 (9):1182-91. doi: 10.1016/S1470-2045(17)30422-9 it is possible to produce knowledge to understand the complex emergence of irAEs better. The ongoing transcriptomic and epigenetic analyses are likely to make invaluable knowledge in this regard.

\section{CONCLUSION}

Immune checkpoint therapy (ICT) is a very promising, recently developed cancer treatment. Here, we described PD-1/PD-L1 and CLTA- 4 immune checkpoints and the monoclonal antibody drug inhibitors that have been approved by the FDA. Although there are positive results in some patients treated with immune checkpoint inhibitors, others never respond to treatment, while the responders often develop resistance. We have described various mechanisms by which resistance can develop and some efforts to overcome this problem. The diverse components of the tumor microenvironment play a critical role in creating ICT resistance. Strategies currently used to help combat resistance include combination therapy with multiple checkpoint inhibitors or checkpoint inhibitors with chemotherapy or radiation.

Given the increasing incidence of cancer, there is an urgent need to improve the currently available therapies and develop new alternatives. Although glucose competition exerts pressure on normal cells in the tumor microenvironment, the fine details about how this affects ICI therapy is still unclear.

\section{AUTHOR CONTRIBUTIONS}

BLR, SAS and STM contributed equally in the, composition of the main text. LD contributed in the conception of article, in intellectual input and in fundraising. $\mathrm{MN}$ is the corresponding author who researched and wrote the final document. All authors contributed to the article and approved the submitted version.

\section{FUNDING}

BLR and LD are funded by The Technology and Human Resources for Industry programme (THRIP). SAS and STM are funded by the National Research Foundation (NRF) GUN: 116681 and GUN: 121878 respectively.

4. Hammers HJ, Plimack ER, Infante JR, Rini BI, McDermott DF, Lewis LD, et al. Safety and Efficacy of Nivolumab in Combination With Ipilimumab in Metastatic Renal Cell Carcinoma: The Checkmate 016 Study. J Clin Oncol: Off J Am Soc Clin Oncol (2017) 35(34):3851-8. doi: 10.1200/ JCO.2016.72.1985

5. Weber JS, D’Angelo SP, Minor D, Hodi FS, Gutzmer R, Neyns B, et al. Nivolumab Versus Chemotherapy in Patients With Advanced Melanoma Who Progressed After Anti-CTLA-4 Treatment (Checkmate 037): A Randomised, Controlled, Open-Label, Phase 3 Trial. Lancet Oncol (2015) 16(4):375-84. doi: 10.1016/S1470-2045(15)70076-8

6. Ansell SM, Lesokhin AM, Borrello I, Halwani A, Scott EC, Gutierrez M, et al. PD-1 Blockade With Nivolumab in Relapsed or Refractory Hodgkin's Lymphoma. New Engl J Med (2014) 372(4):311-9. doi: 10.1056/ NEJMoa1411087 
7. Ansell SM, Hurvitz SA, Koenig PA, LaPlant BR, Kabat BF, Fernando D, et al. Phase I Study of Ipilimumab, an Anti-CTLA-4 Monoclonal Antibody, in Patients With Relapsed and Refractory B-Cell Non-Hodgkin Lymphoma. Clin Cancer Res (2009) 15(20):6446. doi: 10.1158/10780432.CCR-09-1339

8. Sharma P, Retz M, Siefker-Radtke A, Baron A, Necchi A, Bedke J, et al. Nivolumab in Metastatic Urothelial Carcinoma After Platinum Therapy (Checkmate 275): A Multicentre, Single-Arm, Phase 2 Trial. Lancet Oncol (2017) 18(3):312-22. doi: 10.1016/S1470-2045(17)30065-7

9. El-Khoueiry AB, Sangro B, Yau T, Crocenzi TS, Kudo M, Hsu C, et al. Nivolumab in Patients With Advanced Hepatocellular Carcinoma (Checkmate 040): An Open-Label, Non-Comparative, Phase 1/2 Dose Escalation and Expansion Trial. Lancet (2017) 389(10088):2492-502. doi: 10.1016/S0140-6736(17)31046-2

10. Borghaei H, Paz-Ares L, Horn L, Spigel DR, Steins M, Ready NE, et al. Nivolumab Versus Docetaxel in Advanced Nonsquamous Non-Small-Cell Lung Cancer. New Engl J Med (2015) 373(17):1627-39. doi: 10.1056/ NEJMoa1507643

11. Antonia SJ, López-Martin JA, Bendell J, Ott PA, Taylor M, Eder JP, et al. Nivolumab Alone and Nivolumab Plus Ipilimumab in Recurrent Small-Cell Lung Cancer (Checkmate 032): A Multicentre, Open-Label, Phase 1/2 Trial. Lancet Oncol (2016) 17(7):883-95. doi: 10.1016/S1470-2045(16)30098-5

12. Motzer RJ, Tannir NM, McDermott DF, Arén Frontera O, Melichar B, Choueiri TK, et al. Nivolumab Plus Ipilimumab Versus Sunitinib in Advanced Renal-Cell Carcinoma. New Engl J Med (2018) 378(14):127790. doi: 10.1056/NEJMoa1712126

13. Brahmer J, Reckamp KL, Baas P, Crinò L, Eberhardt WEE, Poddubskaya E, et al. Nivolumab Versus Docetaxel in Advanced Squamous-Cell Non-SmallCell Lung Cancer. New Engl J Med (2015) 373(2):123-35. doi: 10.1056/ NEJMoa1504627

14. Robert C, Thomas L, Bondarenko I, O'Day S, Weber J, Garbe C, et al. Ipilimumab Plus Dacarbazine for Previously Untreated Metastatic Melanoma. New Engl J Med (2011) 364(26):2517-26. doi: 10.1056/ NEJMoa1104621

15. Chung HC, Ros W, Delord J-P, Perets R, Italiano A, Shapira-Frommer R, et al. Efficacy and Safety of Pembrolizumab in Previously Treated Advanced Cervical Cancer: Results From the Phase II KEYNOTE-158 Study. J Clin Oncol (2019) 37(17):1470-8. doi: 10.1200/JCO.18.01265

16. Chen R, Zinzani PL, Fanale MA, Armand P, Johnson NA, Brice P, et al. Phase II Study of the Efficacy and Safety of Pembrolizumab for Relapsed/ Refractory Classic Hodgkin Lymphoma. J Clin oncol: Off J Am Soc Clin Oncol (2017) 35(19):2125-32. doi: 10.1200/JCO.2016.72.1316

17. Zinzani PL, Thieblemont C, Melnichenko V, Bouabdallah K, Walewski J, Majlis A, et al. Efficacy and Safety of Pembrolizumab in Relapsed/Refractory Primary Mediastinal Large B-Cell Lymphoma (Rrpmbcl): Updated Analysis of the Keynote-170 Phase 2 Trial. Blood (2017) 130(Supplement 1):2833. doi: 10.1002/hon.2437 49

18. Fuchs CS, Doi T, Jang RW, Muro K, Satoh T, Machado M, et al. Safety and Efficacy of Pembrolizumab Monotherapy in Patients With Previously Treated Advanced Gastric and Gastroesophageal Junction Cancer: Phase 2 Clinical KEYNOTE-059 Trial. JAMA Oncol (2018) 4(5):e180013-e. doi: 10.1001/jamaoncol.2018.0013

19. Balar AV, Castellano D, O’Donnell PH, Grivas P, Vuky J, Powles T, et al. First-Line Pembrolizumab in Cisplatin-Ineligible Patients With Locally Advanced and Unresectable or Metastatic Urothelial Cancer (KEYNOTE052): A Multicentre, Single-Arm, Phase 2 Study. Lancet Oncol (2017) 18 (11):1483-92. doi: 10.1016/S1470-2045(17)30616-2

20. Le DT, Uram JN, Wang H, Bartlett BR, Kemberling H, Eyring AD, et al. PD1 Blockade in Tumors With Mismatch-Repair Deficiency. New Engl J Med (2015) 372(26):2509-20. doi: 10.1056/NEJMoa1500596

21. Zhu AX, Finn RS, Edeline J, Cattan S, Ogasawara S, Palmer D, et al. Pembrolizumab in Patients With Advanced Hepatocellular Carcinoma Previously Treated With Sorafenib (KEYNOTE-224): A Non-Randomised, Open-Label Phase 2 Trial. Lancet Oncol (2018) 19(7):940-52. doi: 10.1016/ S1470-2045(18)30351-6

22. Herbst RS, Baas P, Kim D-W, Felip E, Pérez-Gracia JL, Han J-Y, et al. Pembrolizumab Versus Docetaxel for Previously Treated, PD-L1-Positive, Advanced Non-Small-Cell Lung Cancer (KEYNOTE-010): A Randomised
Controlled Trial. Lancet (2016) 387(10027):1540-50. doi: 10.1016/S01406736(15)01281-7

23. Garon EB, Christofk HR, Hosmer W, Britten CD, Bahng A, Crabtree MJ, et al. Dichloroacetate Should be Considered With Platinum-Based Chemotherapy in Hypoxic Tumors Rather Than as a Single Agent in Advanced non-Small Cell Lung Cancer. J Cancer Res Clin Oncol (2014) 140(3):443-52. doi: 10.1007/s00432-014-1583-9

24. Rini BI, Plimack ER, Stus V, Gafanov R, Hawkins R, Nosov D, et al. Pembrolizumab Plus Axitinib Versus Sunitinib for Advanced Renal-Cell Carcinoma. New Engl J Med (2019) 380(12):1116-27. doi: 10.1056/ NEJMoa1816714

25. Rischin D, Harrington KJ, Greil R, Soulieres D, Tahara M, de Castro G, et al. Protocol-Specified Final Analysis of the Phase 3 KEYNOTE-048 Trial of Pembrolizumab (Pembro) as First-Line Therapy for Recurrent/Metastatic Head and Neck Squamous Cell Carcinoma (R/M HNSCC). J Clin Oncol (2019) 37(15_suppl):6000. doi: 10.1200/JCO.2019.37.15_suppl.6000

26. Kojima T, Muro K, Francois E, Hsu C-H, Moriwaki T, Kim S-B, et al. Pembrolizumab Versus Chemotherapy as Second-Line Therapy for Advanced Esophageal Cancer: Phase III KEYNOTE-181 Study. J Clin Oncol (2019) 37(4_suppl):2. doi: 10.1200/JCO.2019.37.4_suppl.2

27. Nghiem P, Bhatia S, Lipson EJ, Sharfman WH, Kudchadkar RR, Friedlander PA, et al. Durable Tumor Regression and Overall Survival (OS) in Patients With Advanced Merkel Cell Carcinoma (aMCC) Receiving Pembrolizumab as First-Line Therapy. J Clin Oncol (2018) 36(15_suppl):9506. doi: 10.1200/ JCO.2018.36.15_suppl.9506

28. Migden MR, Rischin D, Schmults CD, Guminski A, Hauschild A, Lewis KD, et al. PD-1 Blockade With Cemiplimab in Advanced Cutaneous SquamousCell Carcinoma. New Engl J Med (2018) 379(4):341-51. doi: 10.1056/ NEJMoa1805131

29. Fehrenbacher L, Spira A, Ballinger M, Kowanetz M, Vansteenkiste J, Mazieres J, et al. Atezolizumab Versus Docetaxel for Patients With Previously Treated Non-Small-Cell Lung Cancer (POPLAR): A Multicentre, Open-Label, Phase 2 Randomised Controlled Trial. Lancet (2016) 387(10030):1837-46. doi: 10.1016/S0140-6736(16)00587-0

30. Kaufman HL, Russell J, Hamid O, Bhatia S, Terheyden P, D’Angelo SP, et al. Avelumab in Patients With Chemotherapy-Refractory Metastatic Merkel Cell Carcinoma: A Multicentre, Single-Group, Open-Label, Phase 2 Trial. Lancet Oncol (2016) 17(10):1374-85. doi: 10.1016/S1470-2045(16)30364-3

31. Motzer RJ, Penkov K, Haanen J, Rini B, Albiges L, Campbell MT, et al. Avelumab Plus Axitinib Versus Sunitinib for Advanced Renal-Cell Carcinoma. New Engl J Med (2019) 380(12):1103-15. doi: 10.1056/ NEJMoa1816047

32. Apolo AB, Infante JR, Balmanoukian A, Patel MR, Wang D, Kelly K, et al. Avelumab, an Anti-Programmed Death-Ligand 1 Antibody, in Patients With Refractory Metastatic Urothelial Carcinoma: Results From a Multicenter, Phase Ib Study. J Clin Oncol: Off J Am Soc Clin Oncol (2017) 35(19):2117-24. doi: 10.1200/JCO.2016.71.6795

33. Powles T, O'Donnell PH, Massard C, Arkenau H-T, Friedlander TW, Hoimes CJ, et al. Efficacy and Safety of Durvalumab in Locally Advanced or Metastatic Urothelial Carcinoma: Updated Results From a Phase 1/2 Open-Label Study. JAMA Oncol (2017) 3(9):e172411-e. doi: 10.1001/ jamaoncol.2017.2411

34. Antonia SJ, Villegas A, Daniel D, Vicente D, Murakami S, Hui R, et al. Durvalumab After Chemoradiotherapy in Stage III Non-Small-Cell Lung Cancer. New Engl J Med (2017) 377(20):1919-29. doi: 10.1056/ NEJMoa1709937

35. Ramsay AG. Immune Checkpoint Blockade Immunotherapy to Activate Anti-Tumour T-Cell Immunity. Br J Haematol (2013) 162(3):313-25. doi: 10.1111/bjh.12380

36. Pardoll DM. The Blockade of Immune Checkpoints in Cancer Immunotherapy. Nat Rev Cancer (2012) 12(4):252-64. doi: 10.1038/ nrc3239

37. Walunas TL, Lenschow DJ, Bakker CY, Linsley PS, Freeman GJ, Green JM, et al. CTLA-4 Can Function as a Negative Regulator of T Cell Activation. Immunity (1994) 1(5):405-13. doi: 10.1016/1074-7613(94)90071-X

38. Azuma M, Ito D, Yagita H, Okumura K, Phillips JH, Lanier LL, et al. B70 Antigen Is a Second Ligand for CTLA-4 and CD28. Nature (1993) 366 (6450):76-9. doi: 10.1038/366076a0 
39. Fallarino F, Fields PE, Gajewski TF. B7-1 Engagement of Cytotoxic T Lymphocyte Antigen 4 Inhibits T Cell Activation in the Absence of CD28. J Exp Med (1998) 188(1):205-10. doi: 10.1084/jem.188.1.205

40. Rudd CE, Taylor A, Schneider H. CD28 and CTLA-4 Coreceptor Expression and Signal Transduction. Immunol Rev (2009) 229(1):12-26. doi: 10.1111/ j.1600-065X.2009.00770.x

41. Valk E, Rudd CE, Schneider H. CTLA-4 Trafficking and Surface Expression. Trends Immunol (2008) 29(6):272-9. doi: 10.1016/j.it.2008.02.011

42. Ahmadzadeh M, Johnson LA, Heemskerk B, Wunderlich JR, Dudley ME, White DE, et al. Tumor Antigen-Specific CD8 T Cells Infiltrating the Tumor Express High Levels of PD-1 and Are Functionally Impaired. Blood (2009) 114(8):1537-44. doi: 10.1182/blood-2008-12-195792

43. Fanoni D, Tavecchio S, Recalcati S, Balice Y, Venegoni L, Fiorani R, et al. New Monoclonal Antibodies Against B-Cell Antigens: Possible New Strategies for Diagnosis of Primary Cutaneous B-Cell Lymphomas. Immunol Lett (2011) 134(2):157-60. doi: 10.1016/j.imlet.2010.09.022

44. Xia Y, Jeffrey Medeiros L, Young KH. Signaling Pathway and Dysregulation of PD1 and its Ligands in Lymphoid Malignancies. Biochim Biophys Acta (BBA) - Rev Cancer (2016) 1865(1):58-71. doi: 10.1016/j.bbcan.2015.09.002

45. Parry RV, Chemnitz JM, Frauwirth KA, Lanfranco AR, Braunstein I, Kobayashi SV, et al. CTLA-4 and PD-1 Receptors Inhibit T-Cell Activation by Distinct Mechanisms. Mol Cell Biol (2005) 25(21):9543. doi: 10.1128/MCB.25.21.9543-9553.2005

46. Eldar-Finkelman H. Glycogen Synthase Kinase 3: An Emerging Therapeutic Target. Trends Mol Med (2002) 8(3):126-32. doi: 10.1016/S1471-4914(01) 02266-3

47. Collins M, Ling V, Carreno BM. The B7 Family of Immune-Regulatory Ligands. Genome Biol (2005) 6(6):223. doi: 10.1186/gb-2005-6-6-223

48. Freeman GJ, Long AJ, Iwai Y, Bourque K, Chernova T, Nishimura H, et al. Engagement of the PD-1 Immunoinhibitory Receptor by a Novel B7 Family Member Leads to Negative Regulation of Lymphocyte Activation. J Exp Med (2000) 192(7):1027-34. doi: 10.1084/jem.192.7.1027

49. Salmond RJ. mTOR Regulation of Glycolytic Metabolism in T Cells. Front Cell Dev Biol (2018) 6(122):1-9. doi: 10.3389/fcell.2018.00122

50. Cham CM, Driessens G, O'Keefe JP, Gajewski TF. Glucose Deprivation Inhibits Multiple Key Gene Expression Events and Effector Functions in CD8+ T Cells. Eur J Immunol (2008) 38(9):2438-50. doi: 10.1002/ eji.200838289

51. Chang C-H, Qiu J, O'Sullivan D, Buck MD, Noguchi T, Curtis JD, et al. Metabolic Competition in the Tumor Microenvironment Is a Driver of Cancer Progression. Cell (2015) 162(6):1229-41. doi: 10.1016/j.cell. 2015.08.016

52. Nishimura H, Nose M, Hiai H, Minato N, Honjo T. Development of LupusLike Autoimmune Diseases by Disruption of the PD-1 Gene Encoding an ITIM Motif-Carrying Immunoreceptor. Immunity (1999) 11(2):141-51. doi: 10.1016/S1074-7613(00)80089-8

53. Tivol EA, Borriello F, Schweitzer AN, Lynch WP, Bluestone JA, Sharpe AH. Loss of CTLA-4 Leads to Massive Lymphoproliferation and Fatal Multiorgan Tissue. Immunity (1995) 3(5):541-7. doi: 10.1016/1074-7613 (95)90125-6

54. Peggs KS, Quezada SA, Chambers CA, Korman AJ, Allison JP. Blockade of CTLA- 4 on Both Effector and Regulatory T Cell Compartments Contributes to the Antitumor Activity of Anti-CTLA-4 Antibodies. J Exp Med (2009) 206(8):1717-25. doi: 10.1084/jem.20082492

55. Ramagopal UA, Liu W, Garrett-Thomson SC, Bonanno JB, Yan Q, Srinivasan M, et al. Structural Basis for Cancer Immunotherapy by the First-in-Class Checkpoint Inhibitor Ipilimumab. Proc Natl Acad Sci (2017) 114(21):E4223. doi: 10.1073/pnas.1617941114

56. Wei SC, Levine JH, Cogdill AP, Zhao Y, Anang N-AAS, Andrews MC, et al. Distinct Cellular Mechanisms Underlie Anti-CTLA-4 and Anti-PD-1 Checkpoint Blockade. Cell (2017) 170(6):1120-33.e17. doi: 10.1016/ j.cell.2017.07.024

57. Eggermont AMM, Chiarion-Sileni V, Grob J-J, Dummer R, Wolchok JD, Schmidt H, et al. Prolonged Survival in Stage III Melanoma With Ipilimumab Adjuvant Therapy. New Engl J Med (2016) 375(19):1845-55. doi: 10.1056/NEJMoa1611299

58. Blank C, Gajewski TF, Mackensen A. Interaction of PD-L1 on Tumor Cells With PD-1 on Tumor-Specific T Cells as a Mechanism of Immune Evasion:
Implications for Tumor Immunotherapy. Cancer Immunol Immunother (2005) 54(4):307-14. doi: 10.1007/s00262-004-0593-x

59. Naumann RW, Hollebecque A, Meyer T, Devlin MJ, Oaknin A, Kerger J, et al. Safety and Efficacy of Nivolumab Monotherapy in Recurrent or Metastatic Cervical, Vaginal, or Vulvar Carcinoma: Results From the Phase I/II Checkmate 358 Trial. J Clin Oncol (2019) 37(31):2825-34. doi: 10.1200/JCO.19.00739

60. Janjigian YY, Bendell JC, Calvo E, Kim JW, Ascierto PA, Sharma P, et al. Checkmate-032: Phase I/II, Open-Label Study of Safety and Activity of Nivolumab (Nivo) Alone or With Ipilimumab (Ipi) in Advanced and Metastatic (A/M) Gastric Cancer (GC). J Clin Oncol (2016) 34 (15_suppl):4010. doi: 10.1200/JCO.2016.34.15_suppl.4010

61. Ferris RL, Blumenschein G, Fayette J, Guigay J, Colevas AD, Licitra L, et al. Nivolumab for Recurrent Squamous-Cell Carcinoma of the Head and Neck. New Engl J Med (2016) 375(19):1856-67. doi: 10.1056/NEJMoa1602252

62. Ansell SM, Minnema MC, Johnson P, Timmerman JM, Armand P, Shipp MA, et al. Nivolumab for Relapsed/Refractory Diffuse Large B-Cell Lymphoma in Patients Ineligible for or Having Failed Autologous Transplantation: A Single-Arm, Phase II Study. J Clin Oncol (2019) 37 (6):481-9. doi: 10.1200/JCO.18.00766

63. Anagnostou V, Smith KN, Forde PM, Niknafs N, Bhattacharya R, White J, et al. Evolution of Neoantigen Landscape During Immune Checkpoint Blockade in Non-Small Cell Lung Cancer. Cancer Discovery (2017) 7 (3):264. doi: 10.1158/1538-7445.AM2017-NG01

64. Robert C, Ribas A, Hamid O, Daud A, Wolchok JD, Joshua AM, et al. ThreeYear Overall Survival for Patients With Advanced Melanoma Treated With Pembrolizumab in KEYNOTE-001. J Clin Oncol (2016) 34(15_suppl):9503. doi: 10.1200/JCO.2016.34.15_suppl.9503

65. Makker V, Rasco D, Vogelzang NJ, Brose MS, Cohn AL, Mier J, et al. Lenvatinib Plus Pembrolizumab in Patients With Advanced Endometrial Cancer: An Interim Analysis of a Multicentre, Open-Label, Single-Arm, Phase 2 Trial. Lancet Oncol (2019) 20(5):711-8. doi: 10.1016/S1470-2045 (19)30020-8

66. Le DT, Durham JN, Smith KN, Wang H, Bartlett BR, Aulakh LK, et al. Mismatch Repair Deficiency Predicts Response of Solid Tumors to PD-1 Blockade. Science (2017) 357(6349):409. doi: 10.1126/science.aan6733

67. Garon EB, Rizvi NA, Hui R, Leighl N, Balmanoukian AS, Eder JP, et al. Pembrolizumab for the Treatment of Non-Small-Cell Lung Cancer. N Engl J Med (2015) 372(21):2018-28. doi: 10.1056/NEJMoa1501824

68. Webb ES, Liu P, Baleeiro R, Lemoine NR, Yuan M, Wang Y-H. Immune Checkpoint Inhibitors in Cancer Therapy. J BioMed Res (2018) 32(5):31726. doi: 10.7555/JBR.31.20160168

69. Rosenberg JE, Hoffman-Censits J, Powles T, van der Heijden MS, Balar AV, Necchi A, et al. Atezolizumab in Patients With Locally Advanced and Metastatic Urothelial Carcinoma Who Have Progressed Following Treatment With Platinum-Based Chemotherapy: A Single-Arm, Multicentre, Phase 2 Trial. Lancet (2016) 387(10031):1909-20. doi: 10.1016/S0140-6736(16)00561-4

70. Socinski MA, Jotte RM, Cappuzzo F, Orlandi F, Stroyakovskiy D, Nogami N, et al. Atezolizumab for First-Line Treatment of Metastatic Nonsquamous NSCLC. New Engl J Med (2018) 378(24):2288-301. doi: 10.1056/ NEJMoa1716948

71. Schmid P, Adams S, Rugo HS, Schneeweiss A, Barrios CH, Iwata H, et al. Atezolizumab and Nab-Paclitaxel in Advanced Triple-Negative Breast Cancer. New Engl J Med (2018) 379(22):2108-21. doi: 10.1056/ NEJMoa1809615

72. Horn L, Mansfield AS, Szczęsna A, Havel L, Krzakowski M, Hochmair MJ, et al. First-Line Atezolizumab Plus Chemotherapy in Extensive-Stage SmallCell Lung Cancer First-Line Atezolizumab Plus Chemotherapy in ExtensiveStage Small-Cell Lung Cancer. N Engl J Med (2018) 379: (23):2220-9. doi: 10.1056/NEJMoa1809064

73. Woo SR, Turnis ME, Goldberg MV, Bankoti J, Selby M, Nirschl CJ, et al. Immune Inhibitory Molecules LAG-3 and PD-1 Synergistically Regulate TCell Function to Promote Tumoral Immune Escape. Cancer Res (2012) 72 (4):917-27. doi: 10.1158/0008-5472.CAN-11-1620

74. Wang-Gillam A, Plambeck-Suess S, Goedegebuure P, Simon PO, Mitchem JB, Hornick JR, et al. A Phase I Study of IMP321 and Gemcitabine as the Front-Line Therapy in Patients With Advanced Pancreatic 
Adenocarcinoma. Invest New Drugs (2013) 31(3):707-13. doi: 10.1007/ s10637-012-9866-y

75. He Y, Cao J, Zhao C, Li X, Zhou C, Hirsch FR. TIM-3, A Promising Target for Cancer Immunotherapy. Onco Targets Ther (2018) 11:7005-9. doi: 10.2147/OTT.S170385

76. Wada J, Kanwar YS. Identification and Characterization of Galectin-9, a Novel Beta-Galactoside-Binding Mammalian Lectin. J Biol Chem (1997) 272 (9):6078-86. doi: $10.1074 / j b c .272 .9 .6078$

77. Anderson AC, Joller N, Kuchroo VK. Lag-3, Tim-3, and TIGIT: CoInhibitory Receptors With Specialized Functions in Immune Regulation. Immunity (2016) 44(5):989-1004. doi: 10.1016/j.immuni.2016.05.001

78. Du W, Yang M, Turner A, Xu C, Ferris RL, Huang J, et al. TIM-3 as a Target for Cancer Immunotherapy and Mechanisms of Action. Int J Mol Sci (2017) 18(3):1-12. doi: 10.3390/ijms18030645

79. Gorman JV, Starbeck-Miller G, Pham NL, Traver GL, Rothman PB, Harty JT, et al. Tim-3 Directly Enhances CD8 T Cell Responses to Acute Listeria Monocytogenes Infection. J Immunol (2014) 192(7):3133-42. doi: 10.4049/ jimmunol.1302290

80. Yu X, Harden K C, Gonzalez L, Francesco M, Chiang E, Irving B, et al. The Surface Protein TIGIT Suppresses T Cell Activation by Promoting the Generation of Mature Immunoregulatory Dendritic Cells. Nat Immunol (2009) 10(1):48-57. doi: 10.1038/ni.1674

81. Deuss FA, Gully BS, Rossjohn J, Berry R. Recognition of Nectin-2 by the Natural Killer Cell Receptor T Cell Immunoglobulin and ITIM Domain (TIGIT). J Biol Chem (2017) 292(27):11413-22. doi: 10.1074/jbc.M117. 786483

82. Chauvin JM, Pagliano O, Fourcade J, Sun Z, Wang H, Sander C, et al. TIGIT and PD-1 Impair Tumor Antigen-Specific $\mathrm{CD}^{+} \mathrm{T}$ Cells in Melanoma Patients. J Clin Invest (2015) 125(5):2046-58. doi: 10.1172/JCI80445

83. Huang X, Zhang X, Li E, Zhang G, Wang X, Tang T, et al. VISTA: An Immune Regulatory Protein Checking Tumor and Immune Cells in Cancer Immunotherapy. J Hematol Oncol (2020) 13(1):83. doi: 10.1186/s13045-02000917-y

84. Wang J, Wu G, Manick B, Hernandez V, Renelt M, Erickson C, et al. VSIG-3 as a Ligand of VISTA Inhibits Human T-Cell Function. Immunology (2019) 156(1):74-85. doi: 10.1111/imm.13001

85. Loeser H, Kraemer M, Gebauer F, Bruns C, Schröder W, Zander T, et al. The Expression of the Immune Checkpoint Regulator VISTA Correlates With Improved Overall Survival in Pt1/2 Tumor Stages in Esophageal Adenocarcinoma. Oncoimmunology (2019) 8(5):e1581546. doi: 10.1080/ 2162402X.2019.1581546

86. Böger C, Behrens HM, Krüger S, Röcken C. The Novel Negative Checkpoint Regulator VISTA is Expressed in Gastric Carcinoma and Associated With PD-L1/PD-1: A Future Perspective for a Combined Gastric Cancer Therapy? Oncoimmunology (2017) 6(4):e1293215. doi: 10.1080/2162402X. 2017.1293215

87. Yang S, Wei W, Zhao Q. B7-H3, A Checkpoint Molecule, as a Target for Cancer Immunotherapy. Int J Biol Sci (2020) 16(11):1767-73. doi: 10.7150/ ijbs.41105

88. Picarda E, Ohaegbulam KC, Zang X. Molecular Pathways: Targeting B7-H3 (CD276) for Human Cancer Immunotherapy. Clin Cancer Res (2016) 22 (14):3425-31. doi: 10.1158/1078-0432.CCR-15-2428

89. Huang R-Y, Eppolito C, Lele S, Shrikant P, Matsuzaki J, Odunsi K. LAG3 and PD1 Co-Inhibitory Molecules Collaborate to Limit CD8+ T Cell Signaling and Dampen Antitumor Immunity in a Murine Ovarian Cancer Model. Oncotarget (2015) 6(29):27359-77. doi: 10.18632/oncotarget.4751

90. Lines JL, Pantazi E, Mak J, Sempere LF, Wang L, Connell S, et al. VISTA Is an Immune Checkpoint Molecule for Human T Cells. Cancer Res (2014) 74 (7):1924. doi: 10.1158/0008-5472.CAN-13-1504

91. Prasad DVR, Nguyen T, Li Z, Yang Y, Duong J, Wang Y, et al. Murine B7H3 Is a Negative Regulator of T Cells. J Immunol (2004) 173(4):2500. doi: 10.4049/jimmunol.173.4.2500

92. Marin-Acevedo JA, Kimbrough EO, Lou Y. Next Generation of Immune Checkpoint Inhibitors and Beyond. J Hematol Oncol (2021) 14(1):45. doi: 10.1186/s13045-021-01056-8

93. Schadendorf D, Hodi FS, Robert C, Weber JS, Margolin K, Hamid O, et al. Pooled Analysis of Long-Term Survival Data From Phase II and Phase III Trials of Ipilimumab in Unresectable or Metastatic Melanoma. J Clin Oncol:
Off J Am Soc Clin Oncol (2015) 33(17):1889-94. doi: 10.1200/JCO.2014. 56.2736

94. Schoenfeld AJ, Hellmann MD. Acquired Resistance to Immune Checkpoint Inhibitors. Cancer Cell (2020) 37(4):443-55. doi: 10.1016/j.ccell.2020.03.017

95. Kumar V, Chaudhary N, Garg M, Floudas CS, Soni P, Chandra AB. Current Diagnosis and Management of Immune Related Adverse Events (irAEs) Induced by Immune Checkpoint Inhibitor Therapy. Front Pharmacol (2017) 8(49):1-14. doi: 10.3389/fphar.2017.00049

96. Puzanov I, Diab A, Abdallah K, Bingham CO, Brogdon C, Dadu R, et al. Managing Toxicities Associated With Immune Checkpoint Inhibitors: Consensus Recommendations From the Society for Immunotherapy of Cancer (SITC) Toxicity Management Working Group. J Immunother Cancer (2017) 5(1):95. doi: 10.1186/s40425-017-0300-z

97. El Osta B, Hu F, Sadek R, Chintalapally R, Tang SC. Not All ImmuneCheckpoint Inhibitors are Created Equal: Meta-Analysis and Systematic Review of Immune-Related Adverse Events in Cancer Trials. Crit Rev Oncol Hematol (2017) 119:1-12. doi: 10.1016/j.critrevonc.2017.09.002

98. Hirano F, Kaneko K, Tamura H, Dong H, Wang S, Ichikawa M, et al. Blockade of B7-H1 and PD-1 by Monoclonal Antibodies Potentiates Cancer Therapeutic Immunity. Cancer Res (2005) 65(3):1089.

99. Lipson EJ, Drake CG. Ipilimumab: An Anti-CTLA-4 Antibody for Metastatic Melanoma. Clin Cancer Res (2011) 17(22):6958. doi: 10.1158/ 1078-0432.CCR-11-1595

100. Sambi M, Bagheri L, Szewczuk MR. Current Challenges in Cancer Immunotherapy: Multimodal Approaches to Improve Efficacy and Patient Response Rates. J Oncol (2019) 2019:4508794. doi: 10.1155/2019/4508794

101. Gide TN, Wilmott JS, Scolyer RA, Long GV. Primary and Acquired Resistance to Immune Checkpoint Inhibitors in Metastatic Melanoma. Clin Cancer Res (2018) 24(6):1260. doi: 10.1158/1078-0432.CCR-17-2267

102. Jenkins RW, Barbie DA, Flaherty KT. Mechanisms of Resistance to Immune Checkpoint Inhibitors. Br J Cancer (2018) 118(1):9-16. doi: 10.1038/ bjc.2017.434

103. Fares CM, Van Allen EM, Drake CG, Allison JP, Hu-Lieskovan S. Mechanisms of Resistance to Immune Checkpoint Blockade: Why Does Checkpoint Inhibitor Immunotherapy Not Work for All Patients? Am Soc Clin Oncol Educ Book (2019) 39):147-64. doi: 10.1200/EDBK_240837

104. Fujiwara Y, Mittra A, Naqash AR, Takebe N. A Review of Mechanisms of Resistance to Immune Checkpoint Inhibitors and Potential Strategies for Therapy. Cancer Drug Resistance (2020) 3(3):252-75. doi: 10.20517/ cdr.2020.11

105. Syn NL, Teng MWL, Mok TSK, Soo RA. De-Novo and Acquired Resistance to Immune Checkpoint Targeting. Lancet Oncol (2017) 18(12):e731-e41. doi: 10.1016/S1470-2045(17)30607-1

106. Schumacher TN, Schreiber RD. Neoantigens in Cancer Immunotherapy. Science (2015) 348(6230):69. doi: 10.1126/science.aaa4971

107. Gubin MM, Zhang X, Schuster H, Caron E, Ward JP, Noguchi T, et al. Checkpoint Blockade Cancer Immunotherapy Targets Tumour-Specific Mutant Antigens. Nature (2014) 515(7528):577-81. doi: 10.1038/ nature 13988

108. Tran L, Theodorescu D. Determinants of Resistance to Checkpoint Inhibitors. Int J Mol Sci (2020) 21(5):1-21. doi: 10.3390/ijms21051594

109. de Velasco G, Miao D, Voss MH, Hakimi AA, Hsieh JJ, Tannir NM, et al. Tumor Mutational Load and Immune Parameters Across Metastatic Renal Cell Carcinoma Risk Groups. Cancer Immunol Res (2016) 4(10):820. doi: 10.1158/2326-6066.CIR-16-0110

110. Rizvi NA, Hellmann MD, Snyder A, Kvistborg P, Makarov V, Havel JJ, et al. Mutational Landscape Determines Sensitivity to PD-1 Blockade in NonSmall Cell Lung Cancer. Science (2015) 348(6230):124. doi: 10.1126/ science.aaa1348

111. van Rooij N, van Buuren MM, Philips D, Velds A, Toebes M, Heemskerk B, et al. Tumor Exome Analysis Reveals Neoantigen-Specific T-Cell Reactivity in an Ipilimumab-Responsive Melanoma. J Clin oncol: Off J Am Soc Clin Oncol (2013) 31(32):e439-e42. doi: 10.1200/JCO.2012.47.7521

112. Fu C, Jiang A. Dendritic Cells and CD8 T Cell Immunity in Tumor Microenvironment. Front Immunol (2018) 9:3059. doi: 10.3389/ fimmu.2018.03059

113. Ma Y, Shurin GV, Peiyuan Z, Shurin MR. Dendritic Cells in the Cancer Microenvironment. J Cancer (2013) 4(1):36-44. doi: 10.7150/jca.5046 
114. Wylie B, Macri C, Mintern JD, Waithman J. Dendritic Cells and Cancer: From Biology to Therapeutic Intervention. Cancers (Basel) (2019) 11(4):121. doi: $10.3390 /$ cancers 11040521

115. Vonderheide RH. The Immune Revolution: A Case for Priming, Not Checkpoint. Cancer Cell (2018) 33(4):563-9. doi: 10.1016/j.ccell.2018.03.008

116. Alshamsan A. Induction of Tolerogenic Dendritic Cells by IL-6-Secreting CT26 Colon Carcinoma. Immunopharmacol Immunotoxicol (2012) 34 (3):465-9. doi: 10.3109/08923973.2011.625034

117. Pahne-Zeppenfeld J, Schröer N, Walch-Rückheim B, Oldak M, Gorter A, Hegde S, et al. Cervical Cancer Cell-Derived Interleukin-6 Impairs CCR7Dependent Migration of MMP-9-Expressing Dendritic Cells. Int J Cancer (2014) 134(9):2061-73. doi: 10.1002/ijc.28549

118. Sucker A, Zhao F, Real B, Heeke C, Bielefeld N, Maßen S, et al. Genetic Evolution of T-Cell Resistance in the Course of Melanoma Progression. Clin Cancer Res (2014) 20(24):6593. doi: 10.1158/1078-0432.CCR-14-0567

119. Hulpke S, Tampé R. The MHC I Loading Complex: A Multitasking Machinery in Adaptive Immunity. Trends Biochem Sci (2013) 38(8):41220. doi: $10.1016 /$ j.tibs.2013.06.003

120. Gettinger S, Choi J, Hastings K, Truini A, Datar I, Sowell R, et al. Impaired HLA Class I Antigen Processing and Presentation as a Mechanism of Acquired Resistance to Immune Checkpoint Inhibitors in Lung Cancer. Cancer Discov (2017) 7(12):1420. doi: 10.1158/2159-8290.CD-17-0593

121. Sade-Feldman M, Jiao YJ, Chen JH, Rooney MS, Barzily-Rokni M, Eliane J-P, et al. Resistance to Checkpoint Blockade Therapy Through Inactivation of Antigen Presentation. Nat Commun (2017) 8(1):1136. doi: 10.1038/s41467017-01062-w

122. Rooney MS, Shukla SA, Wu CJ, Getz G, Hacohen N. Molecular and Genetic Properties of Tumors Associated With Local Immune Cytolytic Activity. Cell (2015) 160(1-2):48-61. doi: 10.1016/j.cell.2014.12.033

123. Shin DS, Zaretsky JM, Escuin-Ordinas H, Garcia-Diaz A, Hu-Lieskovan S, Kalbasi A, et al. Primary Resistance to PD-1 Blockade Mediated by JAK1/2 Mutations. Cancer Discovery (2017) 7(2):188. doi: 10.1158/2159-8290.CD16-1223

124. Zaretsky JM, Garcia-Diaz A, Shin DS, Escuin-Ordinas H, Hugo W, HuLieskovan S, et al. Mutations Associated With Acquired Resistance to PD-1 Blockade in Melanoma. N Engl J Med (2016) 375(9):819-29. doi: 10.1056/ NEJMoa1604958

125. Liu D, Jenkins RW, Sullivan RJ. Mechanisms of Resistance to Immune Checkpoint Blockade. Am J Clin Dermatol (2019) 20(1):41-54. doi: 10.1007/ s40257-018-0389-y

126. Gao J, Shi LZ, Zhao H, Chen J, Xiong L, He Q, et al. Loss of IFN- $\gamma$ Pathway Genes in Tumor Cells as a Mechanism of Resistance to Anti-CTLA-4 Therapy. Cell (2016) 167(2):397-404.e9. doi: 10.1016/j.cell.2016.08.069

127. Garcia-Diaz A, Shin DS, Moreno BH, Saco J, Escuin-Ordinas H, Rodriguez GA, et al. Interferon Receptor Signaling Pathways Regulating PD-L1 and PD-L2 Expression. Cell Rep (2017) 19(6):1189-201. doi: 10.1016/ j.celrep.2017.04.031

128. Zajac AJ, Blattman JN, Murali-Krishna K, Sourdive DJD, Suresh M, Altman JD, et al. Viral Immune Evasion Due to Persistence of Activated T Cells Without Effector Function. J Exp Med (1998) 188(12):2205-13. doi: 10.1084/ jem.188.12.2205

129. Blackburn SD, Shin H, Haining WN, Zou T, Workman CJ, Polley A, et al. Coregulation of CD8+ T Cell Exhaustion by Multiple Inhibitory Receptors During Chronic Viral Infection. Nat Immunol (2009) 10(1):29-37. doi: 10.1038/ni.1679

130. Zarour HM. Reversing T-Cell Dysfunction and Exhaustion in Cancer. Clin Cancer Res (2016) 22(8):1856. doi: 10.1158/1078-0432.CCR-15-1849

131. Wherry EJ, Blattman JN, Murali-Krishna K, van der Most R, Ahmed R. Viral Persistence Alters CD8 T-Cell Immunodominance and Tissue Distribution and Results in Distinct Stages of Functional Impairment. J Virol (2003) 77 (8):4911. doi: 10.1128/JVI.77.8.4911-4927.2003

132. Ahn E, Youngblood B, Lee J, Lee J, Sarkar S, Ahmed R. Demethylation of the PD-1 Promoter Is Imprinted During the Effector Phase of CD8 T Cell Exhaustion. J Virol (2016) 90(19):8934. doi: 10.1128/JVI.00798-16

133. Pauken KE, Sammons MA, Odorizzi PM, Manne S, Godec J, Khan O, et al. Epigenetic Stability of Exhausted T Cells Limits Durability of Reinvigoration by PD-1 Blockade. Science (2016) 354(6316):1160. doi: 10.1126/science. aaf 2807
134. Hargadon KM, Johnson CE, Williams CJ. Immune Checkpoint Blockade Therapy for Cancer: An Overview of FDA-Approved Immune Checkpoint Inhibitors. Int Immunopharmacol (2018) 62:29-39. doi: 10.1016/ j.intimp.2018.06.001

135. Koyama S, Akbay EA, Li YY, Herter-Sprie GS, Buczkowski KA, Richards WG, et al. Adaptive Resistance to Therapeutic PD-1 Blockade Is Associated With Upregulation of Alternative Immune Checkpoints. Nat Commun (2016) 7(1):10501. doi: 10.1038/ncomms10501

136. Kakavand H, Jackett LA, Menzies AM, Gide TN, Carlino MS, Saw RPM, et al. Negative Immune Checkpoint Regulation by VISTA: A Mechanism of Acquired Resistance to Anti-PD-1 Therapy in Metastatic Melanoma Patients. Modern Pathol (2017) 30(12):1666-76. doi: 10.1038/ modpathol.2017.89

137. Xia A, Zhang Y, Xu J, Yin T, Lu X-J. T Cell Dysfunction in Cancer Immunity and Immunotherapy. Front Immunol (2019) 10(1719):1-15. doi: 10.3389/ fimmu.2019.01719

138. Li X, Liu R, Su X, Pan Y, Han X, Shao C, et al. Harnessing Tumor-Associated Macrophages as Aids for Cancer Immunotherapy. Mol Cancer (2019) 18 (1):177. doi: 10.1186/s12943-019-1102-3

139. Jiang P, Gu S, Pan D, Fu J, Sahu A, Hu X, et al. Signatures of T Cell Dysfunction and Exclusion Predict Cancer Immunotherapy Response. Nat Med (2018) 24(10):1550-8. doi: 10.1038/s41591-018-0136-1

140. Tanaka A, Sakaguchi S. Targeting Treg Cells in Cancer Immunotherapy. Eur J Immunol (2019) 49(8):1140-6. doi: 10.1002/eji.201847659

141. Wherry EJ, Kurachi M. Molecular and Cellular Insights Into T Cell Exhaustion. Nat Rev Immunol (2015) 15(8):486-99. doi: 10.1038/nri3862

142. Saleh R, Elkord E. Treg-Mediated Acquired Resistance to Immune Checkpoint Inhibitors. Cancer Lett (2019) 457:168-79. doi: 10.1016/ j.canlet.2019.05.003

143. Simpson TR, Li F, Montalvo-Ortiz W, Sepulveda MA, Bergerhoff K, Arce F, et al. Fc-Dependent Depletion of Tumor-Infiltrating Regulatory T Cells CoDefines the Efficacy of Anti-CTLA-4 Therapy Against Melanoma. J Exp Med (2013) 210(9):1695-710. doi: 10.1084/jem.20130579

144. Magnuson AM, Kiner E, Ergun A, Park JS, Asinovski N, Ortiz-Lopez A, et al. Identification and Validation of a Tumor-Infiltrating Treg Transcriptional Signature Conserved Across Species and Tumor Types. Proc Natl Acad Sci (2018) 115(45):E10672. doi: 10.1073/pnas.1810580115

145. Linehan DC, Goedegebuure PS. CD25+ CD4+ Regulatory T-Cells in Cancer. Immunol Res (2005) 32(1-3):155-68. doi: 10.1385/IR:32:1-3:155

146. Viehl CT, Moore TT, Liyanage UK, Frey DM, Ehlers JP, Eberlein TJ, et al. Depletion of CD4+CD25+ Regulatory T Cells Promotes a Tumor-Specific Immune Response in Pancreas Cancer-Bearing Mice. Ann Surg Oncol (2006) 13(9):1252-8. doi: 10.1245/s10434-006-9015-y

147. Hamid O, Schmidt H, Nissan A, Ridolfi L, Aamdal S, Hansson J, et al. A Prospective Phase II Trial Exploring the Association Between Tumor Microenvironment Biomarkers and Clinical Activity of Ipilimumab in Advanced Melanoma. J Transl Med (2011) 9:204. doi: 10.1186/1479-58769-204

148. Pacella I, Procaccini C, Focaccetti C, Miacci S, Timperi E, Faicchia D, et al. Fatty Acid Metabolism Complements Glycolysis in the Selective Regulatory T Cell Expansion During Tumor Growth. Proc Natl Acad Sci USA (2018) 115 (28):E6546-e55. doi: 10.1073/pnas.1720113115

149. Kourepini E, Paschalidis N, Simoes DCM, Aggelakopoulou M, Grogan JL, Panoutsakopoulou V. TIGIT Enhances Antigen-Specific Th2 Recall Responses and Allergic Disease. J Immunol (2016) 196(9):3570. doi: 10.4049/jimmunol.1501591

150. Guan X, Hasan MN, Begum G, Kohanbash G, Carney KE, Pigott VM, et al. Blockade of $\mathrm{Na} / \mathrm{H}$ Exchanger Stimulates Glioma Tumor Immunogenicity and Enhances Combinatorial TMZ and Anti-PD-1 Therapy. Cell Death Dis (2018) 9(10):1010. doi: 10.1038/s41419-018-1062-3

151. Liberti MV, Locasale JW. The Warburg Effect: How Does it Benefit Cancer Cells? Trends Biochem Sci (2016) 41(3):211-8. doi: 10.1016/j.tibs.2015.12.001

152. McLean LA, Roscoe J, Jørgensen NK, Gorin FA, Cala PM. Malignant Gliomas Display Altered Ph Regulation by NHE1 Compared With Nontransformed Astrocytes. Am J Physiol-Cell Physiol (2000) 278(4): C676-C88. doi: 10.1152/ajpcell.2000.278.4.C676

153. Huang Y, Snuderl M, Jain RK. Polarization of Tumor-Associated Macrophages: A Novel Strategy for Vascular Normalization and 
Antitumor Immunity. Cancer Cell (2011) 19(1):1-2. doi: 10.1016/ j.ccr.2011.01.005

154. Farooque A, Afrin F, Adhikari JS, Dwarakanath BSR. Polarization of Macrophages Towards M1 Phenotype by a Combination of 2-Deoxy-DGlucose and Radiation: Implications for Tumor Therapy. Immunobiology (2016) 221(2):269-81. doi: 10.1016/j.imbio.2015.10.009

155. Groth C, Hu X, Weber R, Fleming V, Altevogt P, Utikal J, et al. Immunosuppression Mediated by Myeloid-Derived Suppressor Cells (MDSCs) During Tumour Progression. Br J Cancer (2019) 120(1):16-25. doi: 10.1038/s41416-018-0333-1

156. Lu C, Redd PS, Lee JR, Savage N, Liu K. The Expression Profiles and Regulation of PD-L1 in Tumor-Induced Myeloid-Derived Suppressor Cells. Oncoimmunology (2016) 5(12):e1247135. doi: 10.1080/2162402X.2016. 1247135

157. Meyer C, Cagnon L, Costa-Nunes CM, Baumgaertner P, Montandon N, Leyvraz L, et al. Frequencies of Circulating MDSC Correlate With Clinical Outcome of Melanoma Patients Treated With Ipilimumab. Cancer Immunol Immunother (2014) 63(3):247-57. doi: 10.1007/s00262-013-1508-5

158. Weber R, Fleming V, Hu X, Nagibin V, Groth C, Altevogt P, et al. MyeloidDerived Suppressor Cells Hinder the Anti-Cancer Activity of Immune Checkpoint Inhibitors. Front Immunol (2018) 9:1310. doi: 10.3389/ fimmu.2018.01310

159. Warburg O, Wind F, Negelein E. The Metabolism of Tumors in the Body. J Gen Physiol (1927) 8(6):519-30. doi: 10.1085/jgp.8.6.519

160. Som P, Atkins HL, Bandoypadhyay D, Fowler JS, MacGregor RR, Matsui K, et al. A Fluorinated Glucose Analog, 2-Fluoro-2-Deoxy-D-Glucose (F-18): Nontoxic Tracer for Rapid Tumor Detection. J Nucl Med (1980) 21(7):670-5. doi: 10.1097/00004728-198012000-00045

161. O’Neill LA, Kishton RJ, Rathmell J. A Guide to Immunometabolism for Immunologists. Nat Rev Immunol (2016) 16(9):553-65. doi: 10.1038/ nri.2016.70

162. Frauwirth KA, Riley JL, Harris MH, Parry RV, Rathmell JC, Plas DR, et al. The CD28 Signaling Pathway Regulates Glucose Metabolism. Immunity (2002) 16(6):769-77. doi: 10.1016/S1074-7613(02)00323-0

163. Michalek RD, Gerriets VA, Jacobs SR, Macintyre AN, MacIver NJ, Mason EF, et al. Cutting Edge: Distinct Glycolytic and Lipid Oxidative Metabolic Programs Are Essential for Effector and Regulatory CD4+ T Cell Subsets. J Immunol (2011) 186(6):3299-303. doi: 10.4049/jimmunol. 1003613

164. Fox CJ, Hammerman PS, Thompson CB. Fuel Feeds Function: Energy Metabolism and the T-Cell Response. Nat Rev Immunol (2005) 5(11):84452. doi: $10.1038 /$ nri1710

165. Xia L, Oyang L, Lin J, Tan S, Han Y, Wu N, et al. The Cancer Metabolic Reprogramming and Immune Response. Mol Cancer (2021) 20(1):28. doi: 10.1186/s12943-021-01316-8

166. Sukumar M, Roychoudhuri R, Restifo NP. Nutrient Competition: A New Axis of Tumor Immunosuppression. Cell (2015) 162(6):1206-8. doi: 10.1016/j.cell.2015.08.064

167. Müller B, Fischer B, Kreutz W. An Acidic Microenvironment Impairs the Generation of non-Major Histocompatibility Complex-Restricted Killer Cells. Immunology (2000) 99(3):375-84. doi: 10.1046/j.13652567.2000.00975.x

168. Calcinotto A, Filipazzi P, Grioni M, Iero M, De Milito A, Ricupito A, et al. Modulation of Microenvironment Acidity Reverses Anergy in Human and Murine Tumor-Infiltrating T Lymphocytes. Cancer Res (2012) 72(11):274656. doi: 10.1158/0008-5472.CAN-11-1272

169. Bosticardo M, Ariotti S, Losana G, Bernabei P, Forni G, Novelli F. Biased Activation of Human T Lymphocytes Due to Low Extracellular $\mathrm{Ph}$ is Antagonized by B7/CD28 Costimulation. Eur J Immunol (2001) 31 (9):2829-38. doi: 10.1002/1521-4141(200109)31:9<2829::AIDIMMU2829>3.0.CO;2-U

170. Cerezo M, Rocchi S. Cancer Cell Metabolic Reprogramming: A Keystone for the Response to Immunotherapy. Cell Death Dis (2020) 11(11):964. doi: 10.1038/s41419-020-03175-5

171. Carr EL, Kelman A, Wu GS, Gopaul R, Senkevitch E, Aghvanyan A, et al. Glutamine Uptake and Metabolism Are Coordinately Regulated by ERK/ MAPK During T Lymphocyte Activation. J Immunol (2010) 185(2):1037-44. doi: 10.4049/jimmunol.0903586
172. Zhang J, Pavlova NN, Thompson CB. Cancer Cell Metabolism: The Essential Role of the Nonessential Amino Acid, Glutamine. EMBO J (2017) 36 (10):1302-15. doi: 10.15252/embj.201696151

173. Bonuccelli G, Whitaker-Menezes D, Castello-Cros R, Pavlides S, Pestell RG, Fatatis A, et al. The Reverse Warburg Effect: Glycolysis Inhibitors Prevent the Tumor Promoting Effects of Caveolin-1 Deficient Cancer Associated Fibroblasts. Cell Cycle (2010) 9(10):1960-71. doi: 10.4161/cc.9.10.11601

174. Yarchoan M, Hopkins A, Jaffee EM. Tumor Mutational Burden and Response Rate to PD-1 Inhibition. New Engl J Med (2017) 377(25):25001. doi: 10.1056/NEJMc1713444

175. Ott PA, Hu Z, Keskin DB, Shukla SA, Sun J, Bozym DJ, et al. An Immunogenic Personal Neoantigen Vaccine for Patients With Melanoma. Nature (2017) 547(7662):217-21. doi: 10.1038/nature22991

176. Hung AL, Maxwell R, Theodros D, Belcaid Z, Mathios D, Luksik AS, et al. TIGIT and PD-1 Dual Checkpoint Blockade Enhances Antitumor Immunity and Survival in GBM. Oncoimmunology (2018) 7(8):e1466769. doi: 10.1080/ 2162402X.2018.1466769

177. Guo ZS, Liu Z, Bartlett DL. Oncolytic Immunotherapy: Dying the Right Way Is a Key to Eliciting Potent Antitumor Immunity. Front Oncol (2014) 4:74. doi: $10.3389 /$ fonc.2014.00074

178. Peng M, Mo Y, Wang Y, Wu P, Zhang Y, Xiong F, et al. Neoantigen Vaccine: An Emerging Tumor Immunotherapy. Mol Cancer (2019) 18(1):128. doi: 10.1186/s12943-019-1055-6

179. Whiteside TL, Demaria S, Rodriguez-Ruiz ME, Zarour HM, Melero I. Emerging Opportunities and Challenges in Cancer Immunotherapy. Clin Cancer Res (2016) 22(8):1845. doi: 10.1158/1078-0432.CCR-16-0049

180. Buqué A, Bloy N, Aranda F, Castoldi F, Eggermont A, Cremer I, et al. Trial Watch: Immunomodulatory Monoclonal Antibodies for Oncological Indications. OncoImmunology (2015) 4(4):e1008814. doi: 10.1080/ 2162402X.2015.1008814

181. Chen DS, Hurwitz H. Combinations of Bevacizumab With Cancer Immunotherapy. Cancer J (2018) 24(4):193-204. doi: 10.1097/ PPO.0000000000000327

182. Loo Yau H, Ettayebi I, De Carvalho DD. The Cancer Epigenome: Exploiting its Vulnerabilities for Immunotherapy. Trends Cell Biol (2019) 29(1):31-43. doi: 10.1016/j.tcb.2018.07.006

183. Vétizou M, Pitt JM, Daillère R, Lepage P, Waldschmitt N, Flament C, et al. Anticancer Immunotherapy by CTLA-4 Blockade Relies on the Gut Microbiota. Science (2015) 350(6264):1079-84. doi: 10.1126/science.aad1329

184. Jain T, Sharma P, Are AC, Vickers SM, Dudeja V. New Insights Into the Cancer-Microbiome-Immune Axis: Decrypting a Decade of Discoveries. Front Immunol (2021) 12:622064. doi: 10.3389/fimmu.2021.622064

185. Topalian SL, Taube JM, Anders RA, Pardoll DM. Mechanism-Driven Biomarkers to Guide Immune Checkpoint Blockade in Cancer Therapy. Nat Rev Cancer (2016) 16(5):275-87. doi: 10.1038/nrc.2016.36

186. Doroshow DB, Sanmamed MF, Hastings K, Politi K, Rimm DL, Chen L, et al. Immunotherapy in Non-Small Cell Lung Cancer: Facts and Hopes. Clin Cancer Res (2019) 25(15):4592-602. doi: 10.1158/1078-0432.CCR-18-1538

187. Rimm DL, Han G, Taube JM, Yi ES, Bridge JA, Flieder DB, et al. A Prospective, Multi-Institutional, Pathologist-Based Assessment of 4 Immunohistochemistry Assays for PD-L1 Expression in Non-Small Cell Lung Cancer. JAMA Oncol (2017) 3(8):1051-8. doi: 10.1001/jamaoncol.2017.0013

188. Rizvi NA, Hellmann MD, Snyder A, Kvistborg P, Makarov V, Havel JJ, et al. Cancer Immunology. Mutational Landscape Determines Sensitivity to PD-1 Blockade in Non-Small Cell Lung Cancer. Science (2015) 348(6230):124-8. doi: $10.1126 /$ science.aaa1348

189. Marcus L, Lemery SJ, Keegan P, Pazdur R. FDA Approval Summary: Pembrolizumab for the Treatment of Microsatellite Instability-High Solid Tumors. Clin Cancer Res (2019) 25(13):3753-8. doi: 10.1158/10780432.CCR-18-4070

190. Benci JL, Xu B, Qiu Y, Wu TJ, Dada H, Twyman-Saint Victor C, et al. Tumor Interferon Signaling Regulates a Multigenic Resistance Program to Immune Checkpoint Blockade. Cell (2016) 167(6):1540-54.e12. doi: 10.1016/ j.cell.2016.11.022

191. Tumeh PC, Harview CL, Yearley JH, Shintaku IP, Taylor EJ, Robert L, et al. PD-1 Blockade Induces Responses by Inhibiting Adaptive Immune Resistance. Nature (2014) 515(7528):568-71. doi: 10.1038/ nature 13954 
Conflict of Interest: Authors BLR and LJD were employed by company Buboo (Pty) Ltd.

The remaining authors declare that the research was conducted in the absence of any commercial or financial relationships that could be construed as a potential conflict of interest.
Copyright ( 2021 Russell, Sooklal, Malindisa, Daka and Ntwasa. This is an openaccess article distributed under the terms of the Creative Commons Attribution License (CC BY). The use, distribution or reproduction in other forums is permitted, provided the original author(s) and the copyright owner(s) are credited and that the original publication in this journal is cited, in accordance with accepted academic practice. No use, distribution or reproduction is permitted which does not comply with these terms. 